\title{
Las imágenes del rey y del emperador en Las Siete Partidas \\ y la glosa de Gregorio López
}

\section{The images of king and emperor in Siete Partidas and the gloss of Gregorio López}

\author{
Daniel Alberto PANATERI \\ Doctor de la Universidad de Buenos Aires - Área Historia \\ Imhicihu-Conicet - Universidad de Buenos Aires \\ danielpanateri@gmail.com
}

Recibido: 25 de febrero de 2015

Aceptado: 13 de abril de 2015

\section{RESUMEN}

El siguiente trabajo propone un análisis sobre la manera en la que el texto legal conocido como Siete Partidas trata las imágenes del rey y del emperador. El punto de partida para entender el diverso tratamiento de ambas imágenes es la disociación producida por el discurso jurídico alfonsí sobre estas instituciones (Monarquía e Imperio) en el contexto del Fecho del imperio. Nuestra propuesta será estudiar los modos concretos en los que Alfonso el Sabio construye sus argumentos en las leyes que pretenden regular dichas instituciones. Además, proponemos ver la recepción de este tratamiento en las glosas de Gregorio López del siglo XVI.

PALABRAS CLAVE: Rey, Emperador, Siete Partidas, Fecho del imperio.

\begin{abstract}
The aim of this paper is to show the way in which the Siete Partidas builds the images of the king and the emperor. The starting point to understand the different treatment of these images is the disociation produced by Alphonse's legal discourse upon both institutions (Monarchy and Empire) within the context of the Fecho del Imperio. Thus, our proposal is to study the ways in which Alphonse, the Wise king, builds the arguments of the laws that pretend to regulate these institutions. Moreover, we will study the reception of this treatment in the 16th century gloss of Gregorio López.
\end{abstract}

KEYWORDS: King, Empereor, Siete Partidas, Fecho del imperio.

\section{RÉSUMÉ}

Le travail suivant propose une analyse sur la manière dans laquelle le texte légal connu comme les Siete Partidas traite les images du roi et de l'empereur. Le point de départ pour entendre le divers traitement des deux images est la dissociation produite par le discours juridique alphonsin sur ces institutions (la Monarchie et l'Empire) dans le contexte du Fecho del Imperio. Nôtre proposition sera d'étudier les manières concrètes dans lesquelles Alphonse $\mathrm{X}$, connu comme le roi Savant, construit ses arguments dans les lois que les dites institutions essaient de régler. De plus, nous proposons de voir la réception de ce traitement dans les gloses de Gregorio López du XVI siècle.

MOTS CLÉ : Roi, Empereur, Siete Partidas, Fecho del imperio. 
SUMARIO: 1. Introducción. 2. El problema filológico y una propuesta metodológica. 3 El Imperio como institución desacreditada. 4 Rey y emperador. 5 La institución imperial y monárquica desde la óptica de López. 6. Conclusiones. 7. Anexos.

\section{Introducción}

La propuesta del siguiente estudio es analizar uno de los pilares fundamentales de la tarea jurídica alfonsí desde 1256 en adelante: plantear una imagen de rey y emperador que sirva a efectos de consolidar un frente "nacional" que apoye su candidatura al Sacro Imperio. El punto de partida implica una comparación. Por un lado, aquello que pudo ser planteado por el propio rey Sabio en el siglo XIII y, por el otro, la reapropiación de ese contenido en la edición y glosa de 1555 llevada a cabo por el jurista de Carlos I, Gregorio López. El objetivo de este tipo de análisis es contribuir al entendimiento del funcionamiento del código Siete Partidas dentro de la política española. La razón de esto es la pervivencia de dicha compilación a lo largo de tantos años de monarquía ${ }^{1}$. En este sentido, el puntapié para esta idea se encuentra en que un texto reeditado y re-promulgado tantas veces debe contener una importancia significativa para el medio que lleva a cabo dicha tarea. En rigor, la propuesta pone en primer plano la dimensión del texto de Partidas desde un análisis discursivo de sus leyes y a partir de allí, la funcionalidad de esa letra tanto en su entorno original (por llamarle de algún modo ${ }^{2}$ ) como en una de sus reediciones, quizá la más reputada e importante. Los contextos son bien distintos. Por un lado, el siglo XIII muestra en Castilla una monarquía con pretensiones centralizadoras y, para el caso alfonsí, una intención política concreta alrededor del trono imperial. El siglo XVI, por otro lado, denota una monarquía ya consolidada, más allá de las circunstancias coyunturales, y un rey que es ya emperador del Sacro Imperio. De tal modo, podemos adelantar que las diferencias que encontramos dentro del "mismo texto" no solo referirán a tiempos históricos distintos, explicándose solo por medio de circunstancias culturales diversas,

\footnotetext{
${ }^{1}$ Jesús Rodríguez Velasco, "La urgente presencia de Las Siete Partidas", La Corónica, 38.2, 2010, pp. 97-134, presenta un panorama detallado de todas las instancias de reedición y promulgación del texto de Partidas. Podemos sintetizar y resaltar su primera promulgación conocida en 1348 dentro del Ordenamiento de Alcalá (28.1), la edición de Díaz de Montalvo de 1491 bajo el reinado de los Reyes Católicos y la de López de 1555, que tratamos aquí. Posteriormente hubo reediciones de la de López hasta 1974, excepto en 1808 cuando la Real Academia de la Historia propuso una edición nueva que promulgó Fernando VII.

${ }^{2}$ Con respecto a la tradición manuscrita de Partidas y sus condiciones de existencia durante el reinado del propio Alfonso X véase Alfonso Gallo, "El 'Libro de las Leyes' de Alfonso el Sabio. Del Espéculo a las Partidas", $A H D E, 21-22,1951-52$, pp. 345-528; Alfonso Gallo, "Nuevas observaciones sobre la obra legislativa de Alfonso X", AHDE, 46, 1976; Antonio Bonet, Alfonso X el Sabio, Primera Partida (Manuscrito Add. 20.787 del British Museum), Valladolid; Jerry Craddock, "La cronología de las obras legislativas de Alfonso X el Sabio", AHDE, 51, 1981; Jerry Craddock, The legislative Works of Alfonso $X$, "el Sabio". A critical bibliography, London-Wolfeboro, 1986; entre otros.
} 
sino que dichas diferencias mostrarán divergentes intenciones de tipo políticas que operan sobre el contenido del código jurídico secular más importante de la Península Ibérica.

\section{El problema filológico y una propuesta metodológica}

La transmisión del texto de Las Partidas a lo largo de la historia no puede precisarse de manera lineal ${ }^{3}$. Asimismo, a diferencia de la mayoría de las tradiciones manuscritas que tampoco suelen ser fáciles de asir, este camino complejo y quebrado nos sume, en el estado actual del conocimiento, en la imposibilidad de determinar de manera exacta cuál es la manera en la que se relacionan las versiones conservadas de la Primera Partida. Esta sección fue particularmente modificada a lo largo del tiempo, teniendo en cuenta que se supone como probable la existencia en algún momento entre 1256 y 1272 de un solo texto que pudo circular como Partidas y que sintetizó algunas de las más renovadoras ideas políticas sobre la monarquía emergente del siglo XIII castellano. Este problema llevado hasta el límite nos sugiere que ni siquiera podemos estar seguros de la propia existencia en tiempos de Alfonso X de un texto denominado Las Siete Partidas ${ }^{4}$. En rigor, debemos comenzar aceptando y considerando dos problemas importantes que resultan enigmas y, a la vez, preguntas constitutivas para nuestro estudio: ¿cuál versión circuló originalmente como Las Siete Partidas? y ¿a qué responde la existencia de dos textos sensiblemente disímiles que son asimismo llamados indistintamente de un modo igual?

Al menos desde el siglo XIV circulaban manuscritos, no solo con las variantes sino también con distintas versiones de la Primera Partida, bajo el único nombre de Las Siete Partidas ${ }^{5}$. Estas versiones y variantes no se limitaban a contener las dos

\footnotetext{
${ }^{3}$ Cfr. Alfonso García Gallo, "El 'Libro de las Leyes' de Alfonso el Sabio. Del Espéculo a las Partidas", AHDE 21-22, 1951-52, 345-528; Juan Antonio Arias Bonet, Alfonso X el Sabio, Primera Partida (Manuscrito Add. 20.787 del British Museum), Valladolid, Universidad de Valladolid, 1975; Robert MacDonald, "The Editing of the Alfonsine Juridical Texts: Addendum", La Corónica, 7.2, 1979, 119-20; Jerry Craddock, "La cronología de las obras legislativas de Alfonso X el Sabio", $A H D E, 51,1981$; entre otros.

${ }^{4}$ Alfonso García Gallo, "Nuevas observaciones sobre la obra legislativa de Alfonso X", $A H D E, 46$, 1976, ha llegado a establecer esta hipótesis de la inexistencia de una obra denominada Las Siete Partidas en época de Alfonso X. Sostiene que lo que conocemos hoy por tal obra es, en realidad, producto de un taller denominado con el nombre de alfonsí, pero que habría trabajado entre el último tercio del siglo XIII y principios del XIV. El gran problema de esta intuición es, justamente, la falta de hechos que la correspondan. En este sentido, las críticas de Craddock, "La cronología...", han sido devastadoras y, hasta el momento, nadie ha revitalizado esas hipótesis sin sostén. Esto último, sin embargo, no elimina el problema de la cronología y lo complejo de su determinación, como deja, a su vez, bien claro Craddock. En este sentido, en vista de la imposibilidad material en la que estamos sumidos para dar una respuesta determinante a estos interrogantes, vamos a plegarnos a la mayoría de la crítica y a darle la entidad histórica necesaria a Partidas tal y como la tuvo desde los últimos setecientos años para dar curso a su estudio.

${ }^{5}$ García Gallo, "El libro de las leyes...”, pp. 380.
} 
que, podríamos decir, son opuestos arquetípicos entre sí (ms. Silense y ms. Británico), sino que además se sumaban versiones refundidas que tomaban partes y creaban un nuevo texto ${ }^{6}$. Ninguna de las dos ediciones modernas de la obra ha logrado reparar esta situación 7 . Por el contrario, dichas "ediciones" fueron intentos de estabilizar el texto multiplicado, ajenas a las técnicas filológicas actuales y contribuidoras del proceso de multiplicaxión semántica sobre Partidas.

A estas complicaciones podemos sumar muchas más. Por ejemplo, la profusión de textos refundidos en época de Alfonso XI y su preparación del Ordenamiento de Alcalá en 1348. La producción de manuscritos de Partidas resulta notable para esta época, pero, una vez más, no poseemos elementos empíricos para sostener que esta estabilización se dio por medio de un contenido nuevo no presente ya en la tradición del siglo XIII. Hay que reconocer, igualmente, que no hay datos de la versión sapiencial antes de la inclusión de la obra del rey Sabio en el ordenamiento del nieto ya que el manuscrito Silense debe ser datado en la primera mitad del siglo XIV sin mayores especificaciones. Esta opinión es la que comparte Falhauber según su catálogo ${ }^{8}$ y además es la conclusión a la que llegamos en nuestro estudio paleográfico del manuscrito en el cual discutimos la datación más temprana que expuso Arias Bonet en 1970. La falta de pruebas no nos permite probar ausencias (ad ignorantiam). Por lo tanto, sin la necesidad de incurrir en ceteris paribus, sostenemos que en el estado actual de nuestro conocimiento tenemos dos opciones: cerrar toda posibilidad de análisis de la obra hasta que alguien realice un cotejo completo de todos los manuscritos y las ediciones (que implicaría, necesariamente, encontrar los mss. extraviados); o entender este problema como un elemento constituyente y con el cual hay que lidiar y trabajar a pesar suyo ${ }^{9}$. Naturalmente, nuestra posición es la segunda.

A partir de de dicha posición, que es teórica, se desprende que el análisis sobre la obra de Gregorio López es un análisis sobre la propia obra alfonsí, en el sentido de que por seguro constituye un reflejo de su supervivencia a lo largo del tiempo y de uno de

\footnotetext{
${ }^{6}$ Sin lugar a dudas la principal refundición fue la contenida en el denominado ms. Neoyorkino. Allí, aparece claramente un intento de acoplar y unificar dos versiones. Esto se corrobora por la implementación inacabada, los espacios en blanco y la redacción quebrada de las leyes compartidas. Arias Bonet lo da a conocer en un pequeño artículo ecdótico de 1972, pero todavía se espera un trabajo completo sobre el mismo ("Nota sobre el Códice neoyorkino de la Primera Partida", $A H D E$, 42).

${ }^{7}$ Montalvo y López. Dejamos de lado a Arias Bonet ya que solo transcribe el ms. Británico. Asimismo, dejamos de lado la de Academia, pues nos centramos en el período moderno. De cualquier modo, ver las críticas de Arias Bonet y García Gallo, especialmente a esta última edición.

${ }^{8}$ Nos referimos a PhiloBiblon Project: the romance vernacular sources of medieval and early modern Iberian culture.

${ }^{9} \mathrm{Si}$ bien es necesario aclarar que la mayoría de las variantes y la propia existencia de versiones muy distintas se producen en la I $P$., desde el prólogo hasta el título IV, el resto de la obra no escapa al problema de lagunas, huecos e incapacidad de fijar como verdadero de época alfonsí lo conservado. Ver García Gallo ("El libro de las leyes...", y "La obra legislativa de Alfonso X. Hechos e hipótesis", $A H D E$, 54, 1984), más reciente Jesús Rodríguez Velasco, "La urgente presencia de Las Siete Partidas", La Corónica, 38.2, 2010, 97-134.
} 
sus estadíos particulares, ya que el texto propuesto por López contribuye a profundizar el proceso de multipllicación semántica de Partidas. Actualmente, dicha edición es la más reputada para los historiadores del derecho. Aunque poco nos diga sobre el siglo XIII y quizá sea decididamente un error (por lo menos para la selección que mencionamos) basar estudios sobre lo que Alfonso X pudo decir a partir de esta edición, sí es cierto que el producto del trabajo de Gregorio López nos presentará una serie de elementos explicativos sobre la propia sociedad que la produjo. Más allá de esto último que es en alguna medida autoevidente, resulta de central interés que la edición de López es un estadío del paso de Partidas a través del tiempo. De allí su relevancia y la necesidad de entender la propia naturaleza y función que cumplió dicha edición (su intención, objetivos, etc.) en los años finales del reinado de Carlos I. Entonces, no esperamos que el texto meramente nos hable del contexto sino que pretendemos estudiar un estadío cronológico de un texto que se encontró en constante pervivencia y que ayudó, en tanto discurso de poder, a moldear su contexto de manera dialéctica. Vale decir que la proliferación semántica es notablemente menor para las Partidas subisguientes. Sin embargo, debemos hacer una propuesta que tome en cuenta estos inconvenientes. En tal sentido, nuestro análisis propone partir del escenario de conflicto que tenemos históricamente datado sobre el Fecho del imperio y las aspiraciones de Alfonso X para llegar a la edición del siglo XVI que retoma el texto con la intención de darle un nuevo vuelo.

Por las razones ya enumeradas, debemos entender cuál es la relación que mantiene el texto de Gregorio López con la edición anterior de Montalvo (1491). Por lo tanto, no solo buscaremos las fuentes de López entre los manuscritos conservados sino también entre el texto de la edición anterior, tanto en el texto fuente (atribuido a Alfonso $\mathrm{X}$, Las Partidas), como en la propia glosa, ya que la reedición de Montalvo de 1528 cuenta con un aparato de glosas en latín que cotejamos con las propias de López.

Ahora presentamos los trece manuscritos consultados y las tres ediciones de Las Siete Partidas. Posteriormente los analizamos; confeccionamos el stemma y luego realizamos las ediciones críticas de algunas partes que correspondan a los efectos de nuestras hipótesis. Nuestra intención es mostrar el cotejo completo sobre el prólogo de la obra. Los motivos de la propuesta son que como nuestra intención no es presentar un trabajo ecdótico que abarque la totalidad de la obra, tarea en principio inconmensurable, pensamos en una selección que se ajuste a las necesidades planteadas por nuestro estudio histórico en este artículo. Por lo tanto, todo el análisis está volcado hacia estas hipótesis y no hacia la comprobación de la littera original de Alfonso X en toda la compilación (las siete Partidas). En tal sentido decidimos no continuar agrandando la muestra desde el punto de vista cuantitativo para el mencionado cotejo por creerlo innecesario a efectos de lo que queremos probar. Finalmente, debemos decir que nos conformamos con lo expuesto ya que el prólogo es un elemento central en el armado retórico alfonsí, ganando así importancia estratégica en el análisis ${ }^{10}$.

${ }^{10}$ Cfr. Rafael Cano Aguilar, "Los prólogos alfonsíes", Cahiers de linguistique hispanique médiévale $\mathrm{N}^{\circ} 14-15,1989$, 79-90; Pardo, Madeleine, "Des prologues et des rois. Le 'roi' Alphonse”, Cahiers de 
Asimismo, mostramos una parte de nuestro estudio filológico con la intención de explicitar nuestra preocupación por el problema de la tradición manuscrita y porque es ilustrativo del tratamiento de manuscritos realizado por López. Vale aclarar por tanto, que explicitar el trabajo sobre toda la selección que tratamos infra en la dimensión semántica del análisis implicaría insumir un espacio excesivo e incalculable (baste pensar que hay tesis doctorales enteras dedicadas solo a editar uno o dos títulos de alguna Partida).

La tradición manuscrita de Partidas posee, actualmente, cerca de ochenta y cinco manuscritos. El trabajo que la crítica ha desarrollado dependió de la posibilidad de acceso a ellos. Desde ya que existen grupos de mss. más o menos autorizados sobre cada libro (partida) y hasta de secciones dentro de cada uno (títulos y leyes) que constituyen, a su vez, una condición sine qua non para su estudio. Sobre ellos se ha venido trabajando en los últimos dos siglos ${ }^{11}$. En el caso de la tradición de la Primera Partida conocemos como textos imprescindibles un conjunto de trece mss. ${ }^{12}$ los cuales pueden agruparse de diverso modo. Para esta exposición elijo formar dos grupos según la tendencia más fuerte que en cada uno de ellos se encuentre hacia la versión "sapiencial" o hacia la "legalista". De lo dicho se desprende que haremos caso omiso de las teorías sobre cronología, no porque no nos interesen ni porque no tengamos una postura determinada, sino porque son inconducentes a los efectos de nuestras hipótesis. Aunque, como dijimos, consideramos que los argumentos de Craddock son congruentes según las pruebas físicas que poseemos actualmente, debemos reconocer el estado de conjetura del que aun no han podido pasar ninguna de las teorías enunciadas por la falta, precisamente, de mayores y más conclusivas pruebas. Además, como todos los manuscritos circulaban de manera más o menos indistinta bajo el mismo nombre, las posibles razones de la existencia de versiones carecen de sentido. Por eso, partimos desde su existencia y continuidad a lo largo del tiempo.

linguistique hispanique médiévale, 20, 1995); Juan Ramón Lodares, "El mundo en palabras. Sobre las motivaciones del escritorio alfonsí en la definición, etimología, glosa e interpretación de voces”, Cahiers de Linguistique Hispanique Médiévale 21, 1996, 105-118; Georges Martin, "Alphonse X ou la sciencie politique. Septenaire, 1-11”, Cahiers de Linguistique Hispanique Médiévale. 18-19 y 20, 1993-94 y 1995; Georges Martin, "Alphonse X de Castille, Roi et Empereur. Commentaire du premier titre de la Deuxième partie”, Cahiers de linguistique hispanique médiévale, 23, 2000, 323-48; y Marta Lacomba, "Réécriture et traduction dans le discours d'Alphonse X", Cahiers d'études hispaniques médiévales, 33, 2010; entre otros.

${ }^{11}$ Hago referencia al estudio de Francisco Martínez Marina, Ensayo histórico crítico sobre la antigua legislación y principales cuerpos legales de los reynos de Leon y Castilla, especialmente sobre el código de D. Alfonso el Sabio, conocido con el nombre de las Siete Partidas, Madrid, lbarra, 1808 en adelante.

${ }^{12}$ Dejamos de lado la traducción catalana (Biblioteca del Monasterio de San Lorenzo, El Escorial, MI-2), que conocemos muy bien, ya que no podría haber sido utilizada por los editores españoles del XV y el XVI (Montalvo y López respectivamente). La razón es muy simple: debían traducir (asumiendo que conocieran la variedad dialectal) al castellano aquello que era producto de una traducción al catalán de una obra castellana que, asimismo, tenían ya estos editores, pues dicho ms. se basa en Esc. $1^{\circ}$ y $2^{\circ}$. También dejamos de lado la traducción portuguesa (Alc. 324, Torre do Tombo). 
En referencia al prólogo, nos interesa destacar los siguientes mss. por sus diferencias: ms. Británico (Ms. Add. 20.787, British Museum), Biblioteca Real $3^{\circ}$ (hoy perdido, reproducido solo por la edición de Academia-texto inferior ${ }^{13}$ ), el Neoyorkino (HC 397/573, Hispanic Society) y el de Zabálburu (Vitrina X-131 de la Biblioteca Francisco de Zabálburu y Basabe) para el grupo legalista, al que llamaremos "A". Para el segundo grupo, el sapiencial, que llamaremos "B", los mss.: Silense (hoy ubicado como ms. Espagnol 440 de la Bibliothéque Nationale de Paris $\left.{ }^{14}\right)$, Tol. $1^{\circ}$ (Biblioteca Capitular de Toledo 43-20), Tol. $2^{\circ}$ (BCT 43-13), Tol. $3^{\circ}$ (BCT 43-11). Vitr. 4-6 (Biblioteca Nacional de España), Biblioteca Real $2^{\circ}$ (Biblioteca Nacional de España, Ms. $22^{15}$ ), Esc. $1^{\circ}$ (Biblioteca del Monasterio de San Lorenzo, El Escorial, YIII-21), Esc. $2^{\circ}$ (Z-I-14), Esc. $3^{\circ}$ (Y-III-19) y Ms. 12793 (Biblioteca Nacional). Ahora bien, este agrupamiento, en rigor, no termina de validarse (quizá como otra prueba a la conjetura de Craddock), ya que varios de los testimonios presentan variantes importantes con respecto al resto de los de su versión. Esto sucede principalmente en el epígrafe: el del ms. Tol. $2^{\circ}$ que se acerca al de la versión legalista, por un lado; o los de Esc. $1^{\circ}$, Esc. $2^{\circ}$ y Ms. 22 que mantienen una opción distinta con el agregado de la ascendencia imperial, por el otro. Cabe aclarar que existen casos aparte, como el de Vitr. 4-6, ya que su epígrafe es único, y el del Ms. 12.793 que no posee ninguno.

\footnotetext{
${ }^{13}$ Lamentablemente, aunque lo tenemos en cuenta y lo leemos (lo cotejamos para el texto crítico), no podemos usarlo para el stemma ni para el cuadro 1, ya que vamos a analizar mss. y no podemos pretender analizar algo que no conocemos fielmente.

${ }^{14}$ Ver Juan AntonioArias Bonet, "El códice Silense de la Primera Partida", AHDE, 40, 1970. En este artículo el autor proporciona el paradero del hasta entonces perdido manuscrito de Silos, pero el análisis posterior no parece muy convincente. Por un lado, la idea de dos manos distintas que pertenecieron a distintos tiempos no parece razonable, ya que la letra es clara y definitivamente la misma (lo cual da por tierra con la aseveración de que el ms. proviene en parte del siglo XIII, cosa que también sostiene Academia). Por otro lado, plantea que el deterioro se debe en parte a recortes de las ornamentaciones para "aprovecharlas". Esto resulta desconcertante por dos motivos. En primer lugar, uno se podría preguntar de qué manera podían ser reutilizadas. En segundo lugar, porque el resto de los folios que se encuentran en "perfectas" condiciones muestran dos cosas. La primera, que no hay ornamentaciones. A su vez, cabría decir que si en 1807 la RAH tuvo un códice menos maltratado, como sostiene Arias Bonet, debería haber descrito algo parecido a ornamentaciones, como hizo con todos aquellos mss. con los que trabajó, los cuales describió pertinentemente, pero no da señal de que existieran dichas iluminaciones. La segunda, las manchas de humedad son perfectamente coincidentes con los espacios en blanco de los folios previos, por lo que supongo que lo que pudo haber pasado es que recortaron lo "insalvable" para que no siguiera destruyéndose. Hago referencia a este ms. pues resulta muy reputado y muy citado como el más antiguo de su versión. Ahora bien, su conservación es paupérrima. De hecho, en la propia descripción del manuscrito que realiza Acad. (1807) ya explica lo maltratado que está. La humedad hizo estragos, al punto de que se llevó la mitad de cada plana en el primer cuarto del códice y manchó oscureciendo en gran medida lo restante. Resulta prácticamente imposible llevar adelante una transcripción y/o lectura más o menos certera del testimonio completo. Sin embargo, hemos hecho lo posible y logramos rastrear alrededor de la mitad del prólogo repartido y mezclado entre los folios 6, 7, 8 y 9. Realizamos la transcripción y la utilizamos esperando que alcance para filiar dicho ms.

${ }^{15}$ Previamente fue archivado como D. 34. Así se encuentra, por ejemplo, en el estudio de García Gallo ("El libro de las leyes...", passim).
} 
Los años posibles de redacción serían los siguientes: el más antiguo conservado es el ms. Británico (ca. 1290), Silense (s. XIV), 12793 (s. XIV), Tol. $1^{\circ}$ (s. XIV), Esc. $1^{\circ}$ (1330), Neoyorkino (1340-1360), Tol. $2^{\circ}$ (1344), X-131 (XV), Biblio. Real $2^{\circ}$ (s. XV), Esc. $2^{\circ}(1412)$, Tol. $3^{\circ}$ (1414), Esc. $3^{\circ}(1429)$ y Vitr. 4-6 (1440-1458) ${ }^{16}$.

Una vez dados a conocer los mss. presentes en nuestro estudio, mostramos ahora un cuadro que sintetiza las maneras en las que cada testimonio está compuesto teniendo en cuenta variaciones estructurales que van presentando a lo largo del texto hacia la tendencia "A" (legalista) o "B" (sapiencial):

\section{Cuadro I}

$\begin{array}{lccccccccccccc} & \text { MB } & \text { HC } & \text { X-131 } & \text { Sil. } & \text { Tol } 1^{\circ} & \text { Tol } 2^{\circ} & \text { Tol 3 } & \text { Esc. } 1^{\circ} & \text { Esc. } 2^{\circ} & \text { Esc. } 3^{\circ} & \text { Vitr. 4-6 Biblio. } 2^{\circ} \text { Ms. } 12.793 \\ \begin{array}{l}\text { Epígrafe } \\ \text { Primera }\end{array} & \text { A } & \text { A } & \text { A } & - & - & \text { A } & - & \text { B } & \text { B } & - & \text { C } & \text { A } / \mathrm{B}^{* *} & - \\ \begin{array}{l}\text { parte } \\ \text { prólogo }\end{array} & \text { A } & \text { A } & \text { A } & \text { B } & \text { B } & \text { B } & \text { B } & \text { B*** } & \text { B*** } & \text { B } & \text { B } & \text { B**** } & \text { B } \\ \begin{array}{l}\text { Segunda } \\ \text { parte } \\ \text { prólogo }\end{array} & \text { A } & \text { A } & \text { A } & \text { B } & \text { B* } & \text { B } & \text { B } & \text { A } & \text { A } & \text { B* } & \text { B } & \text { A } & \text { B }\end{array}$

* Si bien la versión es B, termina varias líneas antes.

** No podría decirse que se trate de una refundición, pues además del epígrafe correspondiente a "B", se lee en el margen superior izquierdo por fuera de la caja original de escritura una letra diminuta que copia el epígrafe "A", agregado evidentemente posterior.

*** Esc. $1^{\circ}$ en $1 \mathrm{v}$. b, línea 6 y Esc. $2^{\circ}$ en 1r. b, línea 20 producen cambios en el texto que difieren con todo el resto de los testimonios (por momentos mantiene pocas expresiones, luego las cambia y también agrega. Asimismo, los cambios no indican conexión con la versión A en esa parte del prólogo, ver anexo).

**** Presenta agregados que no se encuentran en ninguno de los demás testimonios.

Es momento de mostrar algunos elementos relevantes del estudio que realizamos para fundamentar la propuesta estemática que habilita la edición que se verá en el anexo. Comenzamos con el grupo "A" que podría encajar con el conocido mote de legalista. Estos son el ms. MB, Biblioteca Real $3^{\circ}, \mathrm{X}-131$ y HC (si bien este último muestra refundición, no lo hace en el prólogo). Cabe recordar lo ya dicho, que el ms. Biblio. Real $3^{\circ}$ está perdido. En este sentido, utilizamos efectivamente el texto expuesto por Academia (inferior), que supone dicho ms. por entero, pero vamos a confeccionar el stemma tomando en cuenta solo tres testimonios, ya que no tenemos ninguna seguridad con respecto a dicho manuscrito ${ }^{17}$. A estos deben sumarse otros:

\footnotetext{
${ }^{16}$ Puede verse la ausencia de datos del $\mathrm{ms}$. Biblioteca Real $3^{\circ}$ que, como ya dije, está perdido y dejamos parcialmente de lado. Esto se debe a que, nuevamente, solo tenemos pruebas de segunda mano para datarlo y no resultan del todo confiables de hecho. Academia lo fecha en el siglo XV. Sin embargo, resulta interesante mencionar que Academia dató el Sil. como del siglo XIII y es del XIV.

${ }^{17}$ Un ejemplo, entre tantos, en el que baso mi desconfianza es en que en la edición nombrada da cuenta del ms. Silense y sin embargo no se colocan en absoluto variantes del mismo, las cuales son imposibles de saltear (ver mi edición crítica del prólogo "B").
} 
Tol. $2^{\circ}$ y Biblio. Real $2^{\circ}$ para el epígrafe, y esos mismos junto a Esc. $2^{\circ}$ en lo que refiere a la parte final del prólogo. Como ya explicamos, Biblio. Real $2^{\circ}$ posee un epígrafe "A" escrito con letra diminuta y por fuera de la caja original del texto, además de que está cortado (quizás comenzó al pie del verso anterior). Por lo tanto, este último está fuera de consideración para filiar. Con respecto a Tol. $2^{\circ}$, todas las variantes que presenta muestran, a su vez, una evidente contaminación con el prólogo "B", por lo cual entendemos que el amanuense agregó pericopas (quizá por parecerle incompleta la fórmula) a partir del prólogo subsiguiente o tenía a la vista los dos epígrafes y los mezcló, amén del agregado de "por la graçia de Dios" que, si bien es una fórmula habitual en la Castilla bajo medieval y moderna, tampoco aparece en el epígrafe "B". Ahora bien, con respecto a la inclusión de Biblio. Real $2^{\circ}$, Esc. $1^{\circ}$ y Esc. $2^{\circ}$ en el final del prólogo, debemos decir que no presenta numerosas variantes. Sin embargo, la única que encontramos es conjuntiva para esos tres testimonios y separativa de la familia "pura" (el agregado final que relevamos en la nota 10 de la edición del prólogo "A"). Dicha variante, es compartida fielmente por estos tres testimonios "no puros". De lo expuesto se desprende la siguiente conclusión: los tres mss. descienden de un subarquetipo sapiencial que estaba contaminado por un subarquetipo de la versión legalista.

Con respecto al cuerpo del prólogo, se encuentran implicados de manera completa tres manuscritos (MB, X-131 y HC). Un primer análisis, de tipo cuantitativo, muestra que MB (que es nuestro optimus) no muestra errores (excepto uno). Por esto, en principio, podemos sostener que es una copia muy cuidada y, con bastante seguridad, del entorno regio. $\mathrm{HC}$, en cambio, muestra diferencias en su disposición y materialidad pero, a su vez, estas diferencias no son filiativas en ningún sentido. X-131 tiene unos primeros dos folios muy cuidados y el texto comienza con muchas iluminaciones y colores, lo cual luego se pierde casi completamente excepto para las capitales. Igual que en los otros casos las diferencias son mínimas pero comparte un error con MB que podría indicar alguna filiación de algún tipo, esto merecerá nuestra atención luego del cuadro 2. En lo que respecta a Biblio. Real $3^{\circ}$, debemos decir que coincide en gran medida con MB pero, una vez más, tampoco expresa variantes filiativas de ningún tipo.

El estudio muestra que a partir de las relaciones expresadas podemos ver que MB coincide con Biblio. Real $3^{\circ}$ en un sesenta por cien. Sin embargo, debemos tener en cuenta la dimensión cualitativa de las variantes. La primera variante relevada muestra una omisión deliberada si tenemos en cuenta la legibilidad del único manuscrito que podemos ver y suponiendo que la edición de Academia lee bien. Una posible hipótesis sería que, en el fallido espíritu de conformar una refundición (naturalmente con resultado más prolongado), HC haya querido ahorrar espacio y eliminar complementos y parataxis de sinónimos. Sin embargo, no podemos afirmar más que eso, aunque podemos comprobar a partir del resto de las variantes que esta tendencia se cumple en el prólogo. Así, omite "et veyendo" y, en varias ocasiones, "mas" (cuando funciona como aumentativo, no adversativo). Sin embargo, muestra una tendencia a agregar 
"et" en cada consecutiva y parataxis que no lo presente. En relación a las variantes de Biblio. Real $3^{\circ}$ encontramos una sola de interés: el cambio que produce de "juzgar" por "gobernar". La posibilidad de copiado directo nos indica que hay otro subarquetipo o bien es un cambio indirecto por sustitución. En relación a la variante por la palabra "rayen"/"trayen", no hay mucho que agregar teniendo presente lo que consignamos en la nota que acompaña dicha variante y no representa un hecho separativo entre Biblio. Real $3^{\circ}$ y HC con MB. Sin embargo, consideramos que es conjuntivo para con X-131. Por lo tanto, concluimos que por la cantidad y cualidad de variantes aportadas no podemos inferir que los manuscritos se relacionan entre sí de manera directa ni que no lo hacen. Sin embargo, por esto mismo y teniendo en cuenta la proliferación de testimonios (aunque no nos hayan llegado todos), hipotetizamos que la pequeña cantidad de variantes y la envergadura de dichas diferencias nos permiten ver que los cuatro testimonios descienden de un mismo arquetipo, pero constituyen ramas relativamente independientes con subarquetipos en medio. A su vez, podríamos agrupar X-131 y MB como una subfamilia, por el hecho de estar muy cerca por el error común ya mencionado. Pasemos ahora a la versión "B".

El análisis cuantitativo realizado sobre los manuscritos de la versión sapiencial ("B") sumado al cualitativo aporta una significativa tendencia que venimos considerando desde el análisis de "A": existe una importante presencia de variantes equipolentes en la mayoría de los mss., y esto nos empuja a pensar que no poseemos sino copias de un entramado complejo de arquetipos, contaminaciones y subarquetipos, y en otros casos, amanuenses con pobres cualidades gramaticales. Sin embargo, nos inclinamos fervientemente por pensar que se cumple mejor la primera idea por sobre la segunda ya que la disposición y materialidad, por ejemplo, del ms. Vitr. 4-6 (el cual posee, a su vez, una gran cantidad de variantes equipolentes -produce el 30,5 por cien de ellas y, en todos los casos, ningún otro ms. las comparte- y muestra severos errores y desatención) parecería indicar que es un texto muy cuidado (materialmente) y producido en un contexto de gran interés por la preservación siendo, posiblemente, perteneciente al taller regio. Además, agregamos que resulta probable que cada testimonio conservado revele que los copistas tomaban como originales varios mss. a la vez. Es decir, se ve mucha contaminación; se puede expresar mejor diciendo que se ven constantes intentos de refundición y/o estabilización. Asimismo, encontramos que el ms. 12793 parecería encontrarse más cercano al Silense; sin embargo, se agrupa dentro de una familia más grande con los tres Toledanos analizados $\left(\beta^{I I}\right)$. En otra familia, pero del mismo subarquetipo podemos encontrar a Esc. $2^{\circ}$ por un lado, y Esc. $1^{\circ}$ y Biblio. Real $2^{\circ}$ por el otro $\left(\beta^{\mathrm{I}}\right)$. En los tres casos, consideramos que el arquetipo de esta familia estaba contaminado por alguno de la versión legalista (pero ninguno de ellos conservados y analizados en este estudio, lamentablemente). Finalmente, existe otro subarquetipo distinto que denominaremos $\alpha$ del cual descienden Vitr. 4-6 y Esc. $3^{\circ}$ (consideramos que debería haber, por lo dicho más arriba, un elemento más entre dicho subarquetipo y Vitr. 4-6). 
Dicho esto, el gráfico final sería el siguiente:

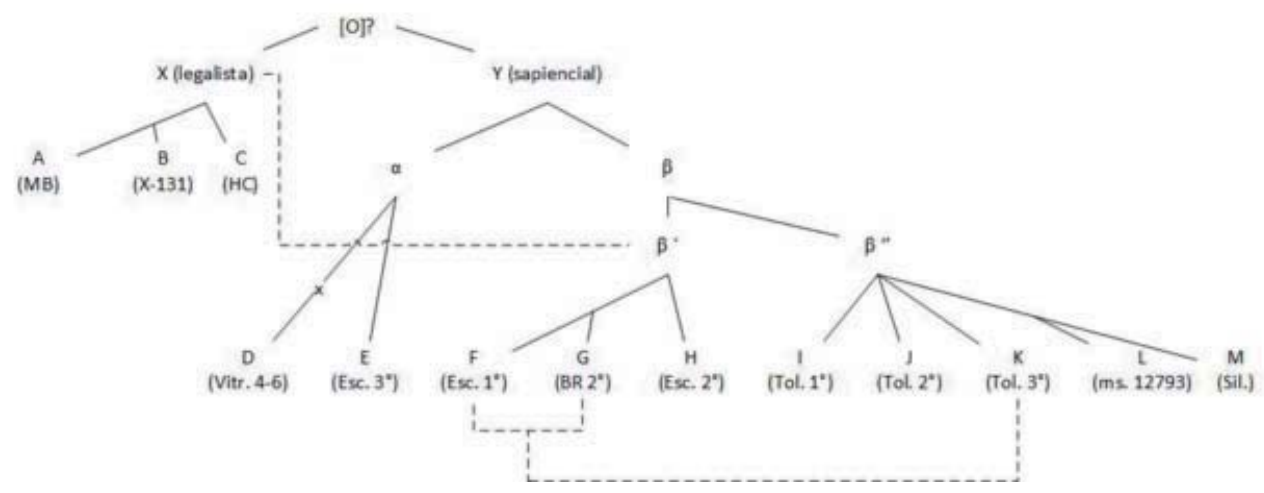

Vamos a fundamentar con mayor profundidad algunos de los elementos originales que se pueden ver en el stemma. Un primer caso interesante es el de la familia de mss. que descienden del subarquetipo $\alpha$. Entre otras variantes filiativas encontramos la siguiente que resulta determinante ya que es conjuntiva y separativa:

"E otrosi, tomamos de los dichos et de los vienes et mercedes que del tenemos primeramente, de los mandamientos et de los castigos que el dixo et mando" (Esc. $3^{\circ}$ )
"E otrosi, de los buenos dichos et mercedes que del rescebimos, primeramente de los mandamientos et castigos que del rescebimos et dexo et mando" (Vitr. 4-6).

Asimismo, la marca (x) en la recta desde el subarquetipo hacia (D) indica una hipótesis: existe un elemento intermedio, pero es imposible de corroborar en el estado actual de nuestro conocimiento. A su vez, otra conjetura probable podría ser que las habilidades gramaticales del copista de Vitr. 4-6 hayan sido paupérrimas (cosa objetable teniendo en cuenta la calidad y el cuidado, así como las iluminaciones, de dicho ms.). El único indicador es la gran cantidad de variantes equipolentes relacionadas con sustituciones que son muy difíciles de comprender a través de la comparación de los pasajes equivalentes en otros testimonios (por ejemplo el consignado en la nota 6 de la edición que estamos explicando).

En referencia a $\beta$ ', vemos que el denominador común es la contaminación con la versión legalista hacia el final del prólogo (notas 23 y 54 edición "B"). La razón de que $\mathrm{E}$ y $\mathrm{F}$ formen una subfamilia está en que omiten "et su merescimiento" y agregan "et el debdo que an con ellos", esta variante es separativa del resto y conjuntiva entre ellos. A su vez, resulta muy interesante la omisión en Esc. $1^{\circ}$ de la segunda "manera de errar" (nota 27 de la edición "B") ya que Esc. $2^{\circ}$ incurre en el mismo error, pero luego hace una llamada y agrega el faltante. Sin embargo, consideramos que es otra mano, posiblemente de lector. Ello nos indica que Esc. $2^{\circ}$ puede ser copia directa de Esc. $1^{\circ}$. Sin embargo, la ausencia de la variante consignada en la nota 20 de la edición que analizamos complejiza un poco las posibles respuestas. Aunque es cierto que las 
lagunas se consideran errores conjuntivos automáticos, nosotros no lo consideramos así. La razón fundamental es que una laguna puede hablar de un antepasado común con igual falta. Ahora bien, los distintos integrantes de esa familia la deberían compartir, pero cuando es muy obvio (como decir "tres razones" y luego solo enumerar dos) un testimonio puede rellenar el faltante (por los medios que sea). Además, este único vestigio que completa puede, a su vez, estar emparentado más con una copia de la misma familia que con otra, ya que pudo completar luego copiando desde allí o por existir un subarquetipo en el medio de la genealogía. Esto último no lo podemos comprobar, pero sí señalamos que hay subfamilia, ya que los errores conjuntivos y separativos que marcamos para $\mathrm{F}$ y $\mathrm{G}$ son más importantes que la laguna compartida entre $\mathrm{F}$ y $\mathrm{H}$ por lo ya explicitado. En conclusión, con los vestigios actuales no podemos separar más, pero la tendencia es que a ese grupo, a su vez, subdividido, hay que estudiarlo más en profundidad. En definitiva, consideramos que sería posible pensar que en el subarquetipo $\beta$ ' había una falta y que BR2 $2^{\circ}$ completó tardíamente. Llegamos a esto (con la esperanza de resolución futura) ya que confiamos mayormente en la conjunción que produce la variante de la nota 20 recién mencionada.

Finalmente debemos decir algunas palabras sobre $\beta$ ". En este subarquetipo encontramos la "esencia" de la versión sapiencial como se la conoce hoy. Aunque valgan dos excepciones: Tol. $1^{\circ}$ indica una transmisión muy compleja (algunos cortes y posiblemente problemas materiales); Tol. $2^{\circ}$ y $3^{\circ}$ muestran una aparente contaminación (pequeña) de la versión legalista, y en el caso de Tol. $2^{\circ}$ esta aserción se cumple por el epígrafe proveniente de la versión "A". Sin embargo, una vez más, creemos que el amanuense es distinto ${ }^{18}$.

Puede verse entonces que en el epígrafe (primera línea) las letras "a" son más redondeadas y las palabras están más estilizadas y extendidas. En el caso de "rey" se ve bien cómo el astil de la "y" cae recto en el epígrafe, mientras que se curva en el prólogo (segunda línea). Por último, vemos que el astil superior de la " $\mathrm{f}$ " tiene una caída en ángulo para el epígrafe, mientras que es casi semicircular en el prólogo.

El caso de contaminación de Tol. $3^{\circ}$ resulta muy evidente, pero con los vestigios que poseemos no podemos asegurar más que eso. Vale aclarar (tal y como se ve en la cita 20 de la edición "B") que el agregado es imperfecto, por eso pensamos en contaminación y no otro tipo de filiación más certera.

Además, los mss. 12.793 y Silense aparecen como subfamilia. Esto parece un poco arriesgado en principio, pero estamos seguros de que se encuentran más cerca entre ellos que de otros de los mss. analizados a partir de la variante consignada en la cita 76 de la edición en cuestión, ya que parece improbable que se dé esa misma adición en ambos mss. sin proceder al menos de un mismo modelo (aunque es menor,

\footnotetext{
${ }^{18}$ Llegamos a esta conclusión por medio del análisis de mínimos sobre muestras de palabras. Lamentablemente, por problemas técnicos no podemos mostrar, con la calidad requerida, las muestras ya que nuestra reproducción fotográfica carece de las condiciones necesarias.
} 
ya que bien podría ser adición por proyección; los ejemplos similares redundan y en general los vestigios son coincidentes en la mayoría de las variantes y en la estructura). En definitiva, dentro del mar de variantes equipolentes las pocas filiativas que existen nos indican una cercanía digna de remarcar. Así, frente a la escasez de pruebas, lejos de permanecer tácitos, contemplamos ciertas hipótesis hasta que tengamos nuevos indicios que permitan confirmar o falsear estas cuestiones.

Finalmente, puede comprobarse que eliminamos de entre nuestros problemas los orígenes a la hora de conformar el stemma. Decidimos colocar las dos tendencias pero sin marcar necesariamente una poligénesis ni tampoco dos o tres redacciones sucesivas ${ }^{19}$. Dicha cuestión, que aún no está zanjada, se encuentra más allá de nuestros propósitos actuales. Cabe repetir que las relaciones consignadas en el stemma se refieren a lo visto en el prólogo, por eso el neoyorquino se marca únicamente como legalista, ya que el prólogo es igual a $\mathrm{MB}$, aunque esta tendencia no se cumple para todo el manuscrito ${ }^{20}$. En caso de que lo consideremos necesario haremos una extensión del análisis a través del procedimiento por calas, ya que palabra por palabra, como realizamos el precedente estudio, resulta insensato a efectos de tiempo y espacio para nuestra hipótesis y nuestro recorte sobre el objeto.

Para cada sección tomamos todos los manuscritos que catalogamos con una misma letra. Vale aclarar que en el aparato se producen cambios.

Esta diversidad de contenido no puede ser puesta en escena a partir de un examen estructural de la obra, por ello, debemos reconstruir el camino realizado por López a través de la comparación sistemática de cada una de las lecciones utilizadas con el fin de llegar, a través de las variantes, a las versiones utilizadas ${ }^{21}$ (ver anexo).

La propuesta metodológica entonces incluye tomar en cuenta el problema filológico y a partir de allí poder ordenar un análisis en torno a un texto probable de Par-

\footnotetext{
${ }^{19}$ La primera es la propuesta de Arias Bonet (“Alfonso X...”) y la segunda es la de Craddock ("La cronología...”).

${ }^{20}$ Ver J.A. Arias Bonet, "Nota sobre el Códice neoyorkino de la Primera Partida", AHDE, 42, 1972.

${ }^{21}$ Sobre el tema de las versiones de Partidas en relación con las obras previas que sirvieron de base para la compilación legal, se debe revisar el problema de la cronología de las obras alfonsíes. A los textos ya citados sobre la cuestión pueden agregarse: Robert MacDonald, "Progress and Problems in Editing Alfonsine Juridical Texts", La Corónica, 6.2, 1978, 74-81; Aquilino Iglesia Ferreirós, “Alfonso $\mathrm{X}$ el Sabio y su obra legislativa. Algunas reflexiones", $A H D E, 50,1980,531-561$; Aquilino Iglesia Ferreirós, "Cuestiones alfonsinas", $A H D E$, 55, 1985, 95-149; Aquilino Iglesia Ferreirós, "Fuero Real y Espéculo", $A H D E, 52,1986$; Aquilino Iglesia Ferreirós, "La labor legislativa del Alfonso X el Sabio", A. García y García (comp.) España y Europa, un pasado jurídico común, Actas del I Simposio Internacional del Instituto de Derecho Común (Murcia, 26/28 de marzo de 1985), edición a cargo de A. Pérez Martín, Murcia, 1986; Joseph O’Callaghan, "Sobre la promulgación del Espéculo y del Fuero Real”, M. Carlé, H. Grassotti \& G. Orduna (eds.), Estudios en homenaje a Don Claudio Sánchez Albornoz en sus 90 años, Buenos Aires, Instituto de Historia de España, 1985; Antonio Pérez Martin, "La obra legislativa alfonsina y puesto que en ella ocupan las Siete Partidas", Glossae. Revista de Historia del Derecho Europeo, 3, 1992; y Emma Montanos Ferrín, España en la configuración histórico-jurídica de Europa, Roma, Il Cigno Galileo Galilei, 1999; entre otros.
} 
tidas y el texto que poseemos en la edición de López para, desde allí, entender las diferencias en las consideraciones sobre rey y emperador, poniendo el énfasis en el proceso de resemantización y deconstrucción argumental que lleva adelante Gregorio López en 1555 con su glosa ${ }^{22}$. Es decir, que el foco hacia el que llevamos la mirada siempre está en la edición y no en el texto fuente.

\section{El Imperio como institución desacreditada}

El Occidente cristiano medieval continental asiste en el siglo XIII a varios procesos muy complejos que, a la vez que le dan forma a la Baja Edad Media, catapultan una serie de elementos que caracterizarán el mundo político, jurídico e ideológico de la temprana Modernidad. Ninguno de estos fenómenos prevalece sobre el resto sino que confluyen dentro de un proceso de larga duración relacionado con la consolidación de monarquías nacionales. Si, como dijo Le Goff ${ }^{23}$, dicho siglo es el del apogeo del cristianismo, vale agregar que también fue el siglo "de cierta nueva obsesión por el archivo, por la escritura, por la copia, por la profesionalización de todo ello y por la laicización de todo el universo que lo hace posible"24. Así, este fenómeno jurídico constituía el modo por el cual el derecho hacía de los cuerpos de la gente, cuerpos documentales haciendo que las personas biológicas existieran, en este mundo poco a poco cada vez más juridizado, en la medida que eran personas jurídicas ${ }^{25}$. Esta nueva forma de dominación por vía del derecho tiene como correlato dos procesos más: la centralización monárquica (en constante y evidente relación con las herramientas jurídicas y su profesionalización) y la desacreditación de la institución imperial. En el contexto de estos dos procesos parecería que la intención de Alfonso X por lograr su elección por vía de la materna sucessio al trono germánico no tendría mucho sentido. Sin embargo, la tarea política llevada a cabo por el rey Sabio consistió en acrecentar y cuando no crear su influencia y eficacia política por medio de la concentración de poder simbólico. Esto no se relaciona solamente con ocupar un lugar de prestigio, sino también con la necesidad de hacer más efectivas sus políticas concretas, lo cual abona la idea del acrecentamiento de la esfera de acción temporal sobre la realidad social.

Como bien plantea Núñez Rodríguez ${ }^{26}$, Alfonso puso grandes esfuerzos en conseguir esta dimensión universalista de poder mediante la postulación de ese pasado

\footnotetext{
${ }^{22}$ Para entender la importancia de la intervención de López, Rafael Gibert, "La glosa de Gregorio López", Historia de la literatura jurídica en la España del Antiguo Régimen, Madrid, Marcial Pons, 2000.

${ }^{23}$ Jacques Le Goff, Le XIII' siècle: L'apogée de la chrétienté, Paris, 1992.

${ }^{24}$ Jesús Rodríguez Velasco, "Diabólicos quirógrafos, o cómo creer la piel de un animal muerto", El Cronista, 40, 2013, pp. 38-48.

${ }^{25}$ Para una perspectiva más completa sobre este proceso acaecido en el siglo XIII véase Jesús Rodríguez Velasco, "Political Idiots and Ignorant Clients. Vernacular Legal Language in Thirteenth-Century Iberian Culture", Digital philology, 2.1, 2013, pp. 86-112.

${ }^{26}$ Manuel Núñez Rodríguez, "El rey, la catedral y la expresión de un programa", Espacio, Tiempo y Forma, VII, 1992, pp. 27-52, y "Non avemos mayor sobre nos en lo temporal: Alfonso X y la imagen de autoridad", Temas Medievales, 3, 1993, pp. 29-46.
} 
imperial glorioso que sustenta la base de construcción ideológica de la unificación monárquica. Los consecuentes cambios que se producen en Partidas son notorios. El primero es el de la inscripción en epígrafes y prólogos de una genealogía imperial de Alfonso; el segundo es el del registro sapiencial que adopta la redacción, el cual no se relaciona solo con su derrota ante los desnaturalizados de Lerma de 1272, sino también con la necesidad de apoyo para la "ida al Imperio"27. Esto nos muestra la relación intrínseca entre proyecto político y cultural en el pensamiento alfonsí.

Toda esta estrategia no implica que del texto de Partidas se deduzca una alta consideración sobre la capacidad de decisión y efectividad del poder imperial a nivel político y jurídico. Sin embargo, lo que en el plano concreto carece de fuerza (limitado margen de acción del emperador), en el plano simbólico conserva toda su potencia, como muestra Siete Partidas. Resulta interesante ver cómo esta lógica de acumulación simbólica recaía con importantes consecuencias sobre la población castellana, particularmente sobre sus bolsillos ${ }^{28}$. En ese sentido, tratamos de entender la manera en la que Alfonso X planteó las instituciones imperial y monárquica.

La presentación en el proemio del título I muestra el habitual respeto por la tradición heredada. Sin embargo, desde el principio coloca en un plano de semejanza la "honrra" de ambas instituciones. Así, "Emperadores e reyes son los mas nobles omes [...]". Prosigue sosteniendo que Dios coloca al rey en la tierra y también al emperador, pero este último por medio del "otorgamiento que le fizieron las gentes", distinción de peso para el sistema de legitimación ideológica bajo medieval ya que en este período comienza a formularse explícitamente la teoría de descendencia directa del poder divino al monarca. Esto obedece a un clima donde la relación directa con el plano de lo divino comienza a funcionar como medio de legitimación del poder tem-

\footnotetext{
${ }^{27}$ Este es otro de los nombres con los que se conoció el conflicto por la corona imperial en época alfonsí. Concretamente, comienza a aparecer esta expresión a partir de la década de 1270 (antes las fuentes solo mencionan el "fecho del imperio"), momento en el cual Alfonso X tuvo la firme convicción de marchar a Italia primero para erigirse como jefe del bando antiangevino (que lo tituló Dei gratia Romanorum rex semper Augustus), pasar por los estados papales y arribar a tierras germánicas con la intención de ser coronado allí. A pesar de contar con la alianza formal con los sectores gibelinos antiangevinos de la Península Itálica, que adoptaron el compromiso de aportar dos mil hombres a la potencial causa bélica del rey Sabio, la marcha hacia el Este no se produjo. Quizá por el temor de no poder prever la reacción del nuevo rey de Francia Felipe III, sobrino de Carlos de Anjou, con la posibilidad de que decidiera intervenir en favor de su sangre directa (aun mediando un acuerdo de no agresión entre Alfonso X y su padre Luis IX y, más aún, siendo familiares en segundo grado). Sin embargo, son solo meras hipótesis y lo único cierto es que todo terminó poco después de comenzar.

${ }^{28}$ Sobre la cuestión del gasto y la ruina económica por los costos en el "fecho del imperio" corrieron ríos de tinta. No vamos a contribuir por nuestra parte en este punto ya que, excede nuestro tema. La bibliografía esencial es Carlos Díez, "Alfonso X y el 'fecho del Imperio", Revista de Occidente, № 43 (ejemplar dedicado a: Alfonso X y su época), 1984, pp. 43-54 por un lado, y Ana Rodríguez López, " Rico fincas de tierra et de muchos buenos vasallos, mas que rey que en la cristiandat ssea'. La herencia regia de Alfonso X", CLHM, 23, 2000, pp. 243-61 por el otro, entre otros, donde se podrán encontrar profusas referencias.
} 
poral, cosa que no consiguen fácilmente los publicistas imperiales debido a los problemas de elección y coronación ${ }^{29}$. Si bien estos elementos son constantemente revisados, la necesidad de la "solución papal" para establecer una legitimidad perdurable es sine qua non. El ejemplo más claro lo constituyen los conflictos militares que fueron necesarios para que Clemente VII coronase a Carlos V en 1527, más allá de la claridad del proceso de elección. En rigor, los elementos rituales relacionados con la unción que Alfonso X se preocupa por desarrollar tienen en este contexto una significación particular. De hecho, Castilla no acostumbraba coronar a sus reyes, excepto casos particulares como Alfonso VII, imperator in regno suo. Y cabe aclarar que cuando se daban estas coronaciones, no se realizaban al inicio del reinado a modo de investidura sino en algún momento requerido por el monarca ya en funciones, con un rito escueto y de poca concurrencia al punto que muchos estudiosos dudan hoy de contabilizarlo como una coronación propiamente dicha ${ }^{30}$.

Sin embargo, su caracterización debe corresponder, en lo referido a la separación de esferas, a la lógica laicista. Por lo tanto, su marcha hacia el vértice del poder simbólico se mantiene intacta. En rigor, Partidas sostiene que el emperador no debe obe-

\footnotetext{
${ }^{29}$ Con respecto a la coronación, el Imperio nunca pudo, sin ver menguadas sus capacidades, deshacerse de la dependencia respecto del papado para efectivizar su poder. En Castilla, esto fue bien distinto. No solo por la ausencia de coronamiento, elemento que muestra una legitimidad operando por otros canales, sino también por el hecho de que cuando se dio este acto tomó un cariz particular centrado en el ingreso al orden de caballería y la autopostulación de los reyes. Sobre esto véase Peter Linehan, "Pseudo-historia y pseudo-liturgia en la obra alfonsina", España y Europa, 1986, Peter Linehan, "Religion, nationalism and national identity in medieval Spain and Portugal", Mews, S. (ed.) Religion and National Identity, Oxford, 1982, y Adeline Rucquoi, Rex, Sapientia, Nobilitas. Estudios sobre la Península Ibérica Medieval, Granada, 2006. En ellos se muestra con profunda dedicación no solo los rituales armados específicamente para cada acto por eclesiásticos españoles, sino también los momentos en los que los propios reyes se salían del acto para mostrar simbólicamente su capacidad creativa. De esta manera, lo habitual es la ausencia de la Iglesia como agente validador y, cuando hay presencia, su constante reducción simbólica a un lugar suplementario. Uno de los mejores y más ilustrativos ejemplos es el cambio que realiza Alfonso XI de los atrios. Mientras que Ramón de Coimbra organizó que el obispo toledano se sentara en alto y observara al monarca desde allí en ascenso hasta sus pies, Alfonso XI lo obligó a sentarse debajo de él y de la reina desde el inicio del ceremonial, mostrando que la naturaleza es superior desde el inicio, i. e. que ya era monarca antes de su corona y que era, en definitiva, superior, al menos al obispo. La fórmula resulta similar a la empleada por el Defensor Pacis, II, XXVI, 11, donde se explica, en defensa de Luis de Baviera, que la coronación no es ad necessitatem sino ad solemnitatem. Además de esto, Alfonso "onceno" elimina la consagración y se coloca la corona a sí mismo y a su reina.

${ }^{30} \mathrm{Al}$ respecto, todo el texto Peter Linehan, "Pseudo-historia y pseudo-liturgia en la obra alfonsina", España y Europa, 1986, proporciona datos sobre la coronación y la unción en la España medieval. Vale aclarar que sería interesante incluir el fenómeno de la autoinvestidura caballeresca, acto que realiza Alfonso X, entre otros, pero que por necesidad metodológica dejamos de lado. Georges Martin, "Control regio de la violencia nobiliaria. La caballería según Alfonso X de Castilla (comentario al título XXI de la Segunda Partida)", Lucha política, condena y legitimación en la España Medieval, CLCHM, anexo 16 (especial), 2004, y Jesús Rodríguez Velasco, Ciudadanía, soberanía monárquica y caballería. Poética del orden de caballería. Madrid, 2009, entre muchos otros, proveen la información necesaria incluyendo amplias referencias a la tradición historiográfica del tema y verdaderamente lo agotan en gran modo.
} 
decer a nadie en lo temporal. No obstante, muestra una lógica de centralización monárquica planteando que el emperador solo manda dentro de los límites de su imperio. En contradicción abierta poco tiempo después, Bartolo de Sassoferrato retoma conceptos previos, en claro ejercicio de reafirmar lo que la publicística imperial ya sostenía desde antaño, diciendo que imperator est dominus totius orbis, quod verum est de iure licet de facto non obediant ${ }^{31}$ (Index...) de igual modo que la glosa ordinaria ad verbum "minime recognoscat" de $X 4,17,3$. Estos son solo algunos ejemplos de la concepción sobre el emperador que pertenecen al período de los posglosadores. Sin embargo, desde el siglo XV será prácticamente imposible sostener tal calificación, como muestra Díaz de Montalvo (1492) en la reproducción de 1542 donde sutilmente indica en la glosa ad verbum "todos" que erat dominus totius mundi $[\ldots]^{32}$.

Alfonso no innova cuando plantea que el emperador debe ser uno, lo cual se explica por cuatro razones en Siete Partidas. La primera, para poder quebrantar los desacuerdos de la multitud para llevarla a la unidad. Este principio sólo sería alcanzable por medio de una unidad de origen que resuelva los conflictos inherentes de la vida social multiplicada. Segunda, para poder hacer leyes y fueros. Sostiene así la monogénesis de la factura de la ley. Este planteo de cuño justinianeo se basa, como tan bien lo explicitó Craddock ${ }^{33}$, de manera directa en la posibilidad o no de que la autoridad monárquica o imperial esté sujeta a esas mismas leyes. La relación es muy clara: la exclusión de la posibilidad de hacer leyes y fueros, que en el discurso alfonsí es lo que comprende por entero al derecho, implica que el «fazedor» es fuente del derecho mismo. Por lo tanto, la ley y su dador son uno. Dicha noción anclada en el Corpus Iuris Civilis, entonces, conlleva la idea del clásico rex legibus solutus est. Tercera razón, para quebrantar a los sobervios [...]. Cuarta, para proteger a la fe cristiana y quebrantar a sus enemigos. Seguidamente, sostiene que el emperador es vicario de Dios para hacer justicia en lo temporal, así como el papa lo es en lo espiritual. Centrémonos momentáneamente en algunas cuestiones de uso y lenguaje.

\section{Rey y emperador}

Alfonso X plantea una serie de diferencias entre rey y emperador. A pesar de considerar que emperadores e reyes son los mas nobles omes e personas e honrra e en poder que todas las otras [...], E porque ellos son asi como començamiento e cabeça

\footnotetext{
31 "El emperador es señor de todo el mundo, lo cual es cierto por derecho, aunque de hecho no le obedezcan".

32 "[El emperador] era señor sobre todo el mundo". La obra de Montalvo fue publicada en 1491, pero esa edición no poseía glosas. Las mismas fueron terminadas en 1492 e incluidas por primera vez en la edición de 1501 y reproducida sin modificaciones hasta 1550.

${ }^{33}$ Jerry Craddock, "Must the King Obey his Laws?", Florilegium Hispanicum: Medieval and Golden Age Studies Presented to Dorothy Clotelle Clarke, Geary, J. (ed.), Madison, Hispanic Seminary of Medieval Studies, 1983, pp. 71-79.
} 
de los otros, queremos primero fablar de ellos (P. II, pr.), debemos ver cómo se percibe un síntoma del descrédito de la institución imperial frente a la monárquica tal y como expusimos más arriba. En este momento del trabajo, es necesario recordar que analizamos un discurso monárquico que específicamente pretende construir lo más sólidamente posible un imaginario ideológico favorable a su posición. Ese es el objeto de nuestro estudio, captar la ideología monárquica en Partidas, desde sus manuscritos a su edición de 1555, y no aseverar que la Edad Media funcionaba como nuestro objeto de estudio lo pretendía ${ }^{34}$.

Para hacer más clara esta exposición vamos a considerar solo cuatro puntos expuestos en la Segunda Partida que reflejan la diferenciación mencionada. En la ley séptima del primer título, se expone que:

Complidas e verdaderas razones mostraron los sabios antiguos porque convino que fuese rey, mas de aquellas que de suso diximos del emperador. E como quier que ante fablamos del por la honrra del imperio que del rey, pero antiguamente primero fueron los reyes que los emperadores $(P$. II, I, 7).

Encontramos aquí dos elementos de ilación en este párrafo introductorio. El primero, "mas de", es un coordinante aditivo que, en este caso, implica que aquello que es establecido como cierto (previo recurso habitual de autoridad a la figura "sabios antiguos") le corresponde un ensanchamiento de capacidades. La trabazón se completa con el coordinante adversativo "pero", que mientras adiciona matiza, en este caso con un rasgo de consecuencia típico del coordinante "demas" que es la forma más utilizada por el discurso alfonsí en esta parte ${ }^{35}$. En efecto, a diferencia del uso más frecuente de la adversativa, cerrar un argumento introduciendo una justificación, en este caso funciona simplemente estableciendo una contraposición con el fin de focalizar esa diferencia: "primero fueron los reyes". En rigor, la acumulación de relativas consiste, no en la incorporación de partes nuevas, sino en la de aquellas ya contenidas en un pasaje previo. El objeto del discurso, en este caso, es el de argumentar una vez más por vía de la preexistencia de la institución monárquica como signo positivo para su definición política. Por tanto, la antigüedad de la institución es un argumento en sí mismo para marcar una condición favorable en el contexto de juego de poderes.

Un segundo elemento podemos encontrarlo hacia el final de la misma ley ${ }^{36}$. En efecto, es un rasgo habitual en la construcción del párrafo alfonsí que la última oración

\footnotetext{
${ }^{34}$ Por ejemplo, todo lo que vamos a tratar aquí, temáticamente, debe ser resuelto tal y como lo hizo Wolf (en Antonio Pérez Martín, "España y Europa, un pasado jurídico común”, Actas del I Simposio Internacional del Instituto de Derecho Común, 1986, pp. 223-58). Allí, consideramos, el autor resuelve muy bien la consideración de Alfonso X sobre el tema cuando explica que no hay diferencia sustancial entre las distintas formas de acceso al trono (elección o sucesión hereditaria), sino que el principio hereditario es una forma determinada de elección y que la elección es una forma especial de herencia.

${ }^{35}$ Esto puede comprobarse por las diferencias con otros mss., por ejemplo Esc. $2^{\circ}, 103 \mathrm{v}$. a.

36 "E tiene el rey lugar de Dios [...] en el reyno, [...], e bien como de suso diximos que lo tiene el emperador en el imperio. E aun de mas, que el rey lo tiene por heredamiento e el emperador por eleccion".
} 
reafirme lo expuesto introduciendo (por adición o consecuencia, muy pocas veces de modo adversativo) una materia nueva que será tratada en la ley siguiente. Así, la ilación se mantiene trabada a lo largo de todo el texto (no solo entre leyes sino, incluso, entre títulos). Es preciso detenernos en la función que tiene el "aun" que lo encabeza. Según Cano Aguilar ${ }^{37}$ esta partícula en el discurso alfonsí sirve como focalizador que parte de una serie de elementos oracionales a una serie de predicados por medio de la secuencialidad y de allí a períodos completos. Así, este uso permite registrar una gradación previa que se intensifica. Implica un escalón más que cambia cualitativamente el valor de la relación entre los elementos de la operación retórica (y de cada uno aislado), a la vez que añade extrañeza y relevancia. En el caso de la oración que cierra la ley, la gradación que implica el "aun" se refuerza con el intensificador "de más": "E aun de mas que el rey lo tiene por heredamiento, e el emperador por eleccion". El formato equivaldría a decir que, entonces, "a todo esto hay que sumarle esto otro", que merece ser focalizado y distinguido por su excepcionalidad. El componente previo es justamente la capacidad de ejercer poder en el territorio competente. Así, vuelve a plantear a modo de constante ese principio de que "aquello que puede el emperador lo puede el rey" y le suma ahora el segundo elemento de distinción, el del derecho sobre el que se origina el poder: la herencia.

El tercer elemento implica la posibilidad del rey del uso casi a voluntad del territorio y todo lo que lo comprende, cosa que no parece tan sencilla para el emperador según la ley VIII de este primer título de la Segunda Partida. La misma comienza así:

Sabida cosa es que todos aquellos poderes que de suso diximos, que los Emperadores han, e deuen auer en las gentes de su Imperio, que essos mismos han los Reyes. Ca ellos non tan solamente son Señores de sus tierras mientra biuen, mas aun a sus finamientos las pueden dexar a sus herederos, porque han el Señorio por heredad, lo que non pueden fazer los Emperadores, que lo ganan por elecion, asi como de suso diximos. E demas, el rey puede dar Villa, o Castillo de su Reyno por heredamiento a quien quisiere, lo que non puede fazer el Emperador.

La fórmula Sabida cosa es que encabeza el pasaje no es frecuentemente utilizada por Alfonso X, ya que resulta más típica la evocatio a elementos concretos que comporten sabiduría de manera excluyente. Sin embargo, consideramos que esta fórmula de encabezado implica una disminución del impacto, que le permite matizar la ancha distancia que traza con la institución imperial. En este punto vuelve una vez más sobre el uso del principio referido ("lo que puede el emperador lo puede el rey") para adicionar diferenciación por esta misma vía y con el mismo conector del primer caso.

${ }^{37}$ Rafael Cano Aguilar, "Los prólogos alfonsíes", Cahiers de linguistique hispanique médiévale $\mathrm{N}^{\circ} 14-$ 15, 1989, pp. 79-90. 
La construcción es sutil, pues engarza este razonamiento con el anterior por medio del "e demas", aditivo que suma información mientras le añade un matiz intensificativo. Este es un uso típico del discurso alfonsí: sumar información por medio de la parataxis y la acumulación de relativas. La manera concreta es la siguiente: dado el último elemento de la ley anterior, se desprenden en la presente ley todas las consecuencias del estado descripto. Así, al heredamiento del reino como forma superior de legitimidad de origen en el ejercicio del poder se le suman (a la vez que se resaltan con el intensificador) todas las bondades que se desprenden necesariamente de allí: "el rey puede dar villa", "el rey puede dar castillo", "el rey se puede servir e ayudar de las gentes del reyno", etc.

El cuarto elemento a destacar se encuentra dentro del listado, pero genera tal focalización que merece estar aparte. Cuando establece esta larga lista de cosas que el rey puede hacer y el emperador no, la ley parece centrar la atención en la cuestión fiscal:

Ca el por ninguna cuyta que le venga, non puede apremiar a los del Imperio que le den mas de aquello, que antiguamente fue acostumbrado de dar a los otros Emperadores, si de agrado dellos non se fiziere. Mas el rey puede demandar, e tomar del reyno lo que usaron los otros reyes que fueron ante que él, e aún más.

Como vemos, utiliza la partícula "ca", la cual implica consecuencia lógica. Sin embargo, en este caso inicia una negación. La fórmula que prosigue es la siguiente: para cada elemento del listado que a priori el lector sabe que responde a las facultades exclusivas del rey, le sigue la negación de que el emperador pueda hacerlo. El peso de la parataxis, entonces, resulta de importancia. Asimismo, al llegar al momento de sostener que el rey puede aumentar a voluntad los impuestos, coloca la conjunción "ca", la cual, según los estudios de Lacomba ${ }^{38}$, es utilizada para condensar lo esencial de la argumentación. De este modo, lo que plantea es que la conjunción «ca» relaciona elementos oracionales entre sí de modo causal de manera encadenada y, con el soporte constante de la parataxis, para sustituir enunciados finales por enunciados causales. Este procedimiento genera una focalización al explicitar el razonamiento y exaltar la razón de lo dicho, en este caso, al comienzo de la ley.

Hemos seleccionado todos estos elementos en virtud de la claridad con que son expuestos en la obra legal. Nuestro análisis no se centra en el contenido, el cual es por momentos trillado o contradictorio, otras veces inocente. Por el contrario, nuestra intención es mostrar cómo, en lo momentos en los que el contenido semántico no muestra mucha innovación, se hace presente sin embargo un modelo de escritura que, para la efectividad del discurso, utiliza como principio de autoridad el razonamiento

\footnotetext{
${ }^{38}$ Marta Lacomba, "Un discours historique marqué par la causalité: 1'utilisation de la conjonction $c a$ dans l'Estoria de España d'Alphonse X", CLCHM, No 27, 2004, pp. 71-82.
} 
encadenado. A lo largo del resto de la Segunda Partida podemos encontrar muchos casos similares agregando elogios a la monarquía.

El objetivo de nuestro análisis es mostrar todos los ángulos diversos desde los cuales Partidas monta un aparato complejo de funcionamiento que obedece a formas y leyes específicas y que no se agotan en un mero mensaje concreto para un interlocutor específico de su tiempo. Finalmente, cabe remarcar que hay dos niveles en este texto. Por un lado, la exaltación de la figura imperial por dos vías. La primera, su contraposición al papado en tanto que, como cualquier otro poder temporal, solo debe cuentas de un modo directo a Dios, que es el fundamento de su existencia (en el caso de la elección imperial esto toma otro cariz). Segundo, por medio de la atestiguación histórica de preexistencia institucional. Este afán, repetidamente buscado también por medio de las obras historiográficas, encuentra eco en las necesidades argumentales de Alfonso X. El otro nivel lo constituye el matiz expuesto entre el Imperio y la monarquía. Al igual que lo hace en la Primera Partida, aquí nuevamente subvierte los objetivos expuestos por los condicionamientos ideológicos del gran plan político que está detrás del proceso compilatorio general de la obra. Por esto, tal y como planteamos al principio, el ordenamiento tiene el fin de acumular poder simbólico, el cual no obedece solamente a las necesidades narrativas de crear imaginería para librar el combate en un plano meramente discursivo. Al contrario, la intención es plantar ideología (no debemos olvidar que la idea era que este texto funcionase como un cuerpo de derecho legible y aplicable en cortes y juzgados) para generar una mejora en la capacidad concreta de ejercicio del poder. El proceso es aquél que obedece a una dialéctica del orden. Primero, plantea una fotografía de la sociedad, la cual es la mayoritariamente aceptada y, luego, pone en marcha esa imagen por medio de una ilación sutil y elaborada para conseguir establecer series consecutivas que vayan llevando al lector indefectiblemente por donde el texto lo desea. Finalmente, enfrenta al lector a la posición última por vía de la consecuencia, generando así un efecto de verdad inapelable y que contradice mucho del orden tradicional que aquella (ya olvidada) fotografía mostraba.

Veamos otras diferencias entre las instituciones planteadas en el texto jurídico glosado por López en el siglo XVI.

\section{La institución imperial y monárquica desde la óptica de López}

Vamos a ver ahora cómo este funcionamiento del siglo XIII es utilizado en el siglo XVI. Alfonso X establece que:

El poderio que el emperador ha es en dos maneras. La una de derecho. E la otra de fecho, e aquel que ha segund derecho es este que puede fazer ley e fuero nueuo, e mudar el antiguo [...] E puede otrosi toller la costumbre usada [...] e fazer nueua [...] E aun ha poder de fazer justicia e escarmiento en todas las tierras del imperio [...] E otro ninguno non lo puede fazer si non aquellos a quien 
lo el mandasse o a quien fuesse otorgado por priuilegio [...] E deue batir moneda en el imperio. E maguer muchos grandes señores lo obedescen, non lo puede ninguno fazer en su tierra, [...] E el solo es, otrosi, poderoso de partir los terminos de las provincias e de la villas. E por su mandado deuen fazer guerra, tregua e paz. $(P ., \mathrm{II}, \mathrm{I}, 2)$.

A diferencia de la dinámica que podríamos encontrar mayormente desarrollada en la Segunda Partida, Gregorio López en la glosa ad verbum "escarmiento" da muestras de apoyo al planteo alfonsí. La temática, a efectos de fortalecer la imagen del poder monárquico hacia el interior permite que el jurista del siglo XVI acepte las formulaciones del rey castellano del siglo XIII, pues no entran en contradicción con las lógicas imperiales que en otros pasajes discute. Además, cuando la letra no da lugar a problemas con el papado, el jurista del siglo XVI decide reafirmar lo expuesto en el cuerpo del texto comentado explicitando que la jurisdicción es suprema, ya que entiende esta intervención de "dar escarmiento" como la exposición del mero y mixto imperio. Esta forma jurisdiccional se basa en considerar, desde una teoría clásica, al emperador y al rey sin superior en lo temporal como fuente misma de esa capacidad ${ }^{39}$. En este punto puede verse un cambio en el pensamiento político de base. La propuesta de Alfonso, cuando iguala y sostiene estos poderes, refiere a esa capacidad hispánica de constituir un vínculo político natural ${ }^{40}$. En consecuencia, entiende al poder imperial como delegado, pero basado en los naturales de la tierra, los viejos romanos, nuevo germanos. Sin embargo, cuando López apoya la misma idea, el planteo lo realiza sobre la base de la teoría política heredada del concepto papal otorgado al rey francés en virtud de su Per Venerabilem. Las consecuencias son las mismas, los medios han cambiado. La teoría política que sustentaba el poder monárquico castellano ya no existe y la corona española basa su potestad en torno a conceptos propios y habituales de la época, porque se han desplegado, a su vez, hasta el punto de dejar de ser materia de conflicto.

En la glosa ad verbum "privilegio", plantea una retroversión de la jurisdicción de los señores al emperador o al rey. En este sentido, no hace más que reafirmar lo dicho en la glosa anterior y darle entidad completa a esta concepción:

Et not. in terris dominorum, rex fundat intentionem super iurisdictionem, unde ex sola negligentia eorum iurisdictio reuertitur ad ordinariam et regiam

\footnotetext{
${ }^{39}$ En la bula Per venerabilem de 1202 de Inocencio III, se sostiene que el rey de Francia no tiene superior en lo temporal. Véase Raquel Kritsch, Soberania: a construção de um conceito, San Pablo, 2002.

${ }^{40}$ Adeline Rucquoi, "De los reyes que no son taumaturgos: los fundamentos de la realeza en España", Temas Medievales, 5, 1995, pp. 163-186, Georges Martin, "Control regio de la violencia nobiliaria. La caballería según Alfonso X de Castilla (comentario al título XXI de la Segunda Partida)", Lucha política, condena y legitimación en la España Medieval, CLCHM, anexo 16 (especial), 2004, y Georges Martin, "Le concept de 'Naturalité' dans les Sept Parties d'Alphonse X le Sage", Construir la identidad en la Edad Media. Poder y memoria en la Castilla de los siglos VII a XV, Cuenca, 2010, pp. 145-163.
} 
a qua emanauit [...] hoc casu non propriem sit deuolutio, sed recuperatio aut potius reuersio ad pristinus status $[\ldots]^{41}$.

Esta coincidencia pone en primer plano justamente esta dinámica de desarrollo de un planteo jurisdiccional que está completamente asociado a ese lugar absoluto. De tal modo, esta capacidad jurídica regia de intervención se produce por el propio derecho que está en la base de ese poder. En ese sentido, la noción de que lo que se produce es una reversión implanta un concepto distinto al de superioridad, ya que niega la existencia de tal condición para los señores. Jurisdicción, entonces, es condición del rey, no uno de tantos elementos componentes del orden social. El vocabulario permanece pero el sentido es otro.

En rigor, la cuestión de fondo es la reafirmación del monarca de su autoridad última y absoluta sobre el espacio de poder. En este sentido, la palabra fundat da muestras del orden en el que se intenta plantear la relación entre jurisdicción y majestas. Una vez más, el intento es el de ubicar dentro del territorio del reino una noción plena de potestad legislativa, es decir, una suerte de "superjurisdicción", que adquiere en el siglo XIII el planteo de jurisdicción concéntrica. Esto, que no es otra cosa que la centralización, implicará una diferencia cualitativa como corolario. En otras palabras, el planteo alfonsí da muestras de un estado de cosas que implican a esta jurisdicción centralizada. Esto es entendido por López en 1555 de manera sencilla y asociado de modo automático.

En la ley tercera, Alfonso plantea que:

Poderoso deue el Emperador ser de fecho de manera que el su poder sea tan cumplido e assi ordenado que pueda mas que los otros de su sennorio para apremiar e costrennir a los que non quisieren obedescer. E para auer tal poder como este ha menester que se ensennoree de las cauallerias e que las parta e encomiende a tales cabdillos que le amen e que las tengan por el, e de su mano, de manera que conozcan a el por su señor, e a los otros que los cabdillan por

\footnotetext{
41 "Y nótese que en las tierras de los señores el rey establece [posibilidad jurídica (¿derecho?)] intervención legal sobre [la base de] su jurisdicción, de donde se sigue que de la sola indiferencia de estos, la jurisdicción vuelve a la ordinaria y regia, de la cual emanaba. En este caso, no hay una devolución, sino propiamente recuperación o mejor reversión al estado primigenio". N. b. hay dos cuestiones a destacar en la traducción. En primer lugar, definimos la noción de intentio en virtud de su etimología, i. e., intervención. Pero, le agregamos su condición de "jurídico" en la medida que los diccionarios establecen con poca claridad una serie de acepciones posibles que solo tienen en común la idea de ser un vocablo de uso jurídico. Así, Blaise otorga la idea de "voluntad" y Niermeyer, s. v. 6, legal claim así como prosecution y impeachment. En segundo lugar, establecemos que jurisdicción se refiere al concepto jurídico-político de capacidad propiamente regio por dos motivos. El primero es que no encontramos, en general, un uso de iurisdictio como pasible de ser aplicado a los poderes por debajo del rey en los escritos de López. Segundo, y más importante, que dominorum está en plural y iurisdictionem es singular. Por tanto, si bien puede haber error de copista, ya que iurisdictiones sería su plural, asociando esto a lo primero, confirmamos nuestra interpretación.
} 
guiadores. E otrosi deue ser poderoso de los castillos e de las fortalezas e de los puertos del imperio e mayormente de aquellos que estan en frontera de los barbaros e de los otros reynos [...] porque en su mano e en su poder sean toda via, las entradas e las salidas del imperio (P. II, I, 3).

Esta ley muestra también la tremenda necesidad, y nunca olvidada, del control político concreto de las cosas. En algún punto, este es el principio motor de la construcción de poder simbólico en su correspondencia de facto. Aquello que asegura y plantea el derecho debe expresarse también desde sus necesidades concretas de generar ese orden y obediencia.

En la ley que sigue, explica Alfonso que:

Rey tanto quiere dezir como regidor, ca sin falla a el pertenesce el gouernamiento del reyno. E segund dixeron los sabios antiguos e sennaladamente Aristoteles en el libro que se llama politica, en el tiempo de los gentiles, el Rey non tan solamente era guiador e cabdillo de las huestes e juez sobre todos los del reyno, mas aun era señor en la cosas espirituales que entonces se fazian por reuerencia e por honrra de los dioses en que ellos creyan. E por ende los llamauan Reyes, porque regian tambien en lo temporal como en lo spiritual. E sennaladamente tomo el Rey nome de nuestro señor Dios, ca asi como el es dicho Rey sobre todos los Reyes porque del han nome, e los gouierna e los mantiene en su lugar en la tierra para fazer justicia e derecho, asi ellos son tenudos de mantener e de guardar en justicia e en verdad a los de su sennorio (P. II, I, 6).

Este pasaje plantea un argumento de historicidad para otorgar veracidad a su propuesta. De este modo, no hay un planteo positivo de esa doble función, sino su adscripción a un momento previo a la venida de Cristo. Tal procedimiento, sumado a la igualación de la institución monárquica divina con la humana, le otorga presencia atemporal a esta forma de gobierno. Esta igualación se realiza a través del argumento de la instauración de la misma por el propio Dios como fundamento y naturaleza de ese vínculo para su dominio sobre el mundo. La estructura argumentativa es muy eficaz: primero, introduce el objeto por medio del recurso etimológico ("regidor") que le permite plantear esa superioridad monárquica y, a través de la subordinación consecutiva ("por ende") introduce el fundamento para afirmar la doble dimensión constitutiva de la institución monárquica (regir lo temporal y lo espiritual) como una derivación lógica de la estructura expositiva anterior. Corona la construcción argumental con la conjunción "ca", la cual le permite introducir un antecedente argumental, i.e. la causa a través de la cual postula, por medio de otra subordinación en clave lógica (encabezada por "asi"), la analogía funcional entre la construcción divina de la monarquía y su correlato en la tierra. La utilidad concreta de esto implica no una pretensión cesaropapista, sino una marca de superioridad que coloca al reino como la unidad esencial y natural, natura id est Deus. 
Sin embargo, en la recepción (y nueva promulgación) de esta obra en siglo XVI, Gregorio López hace una crítica al planteo alfonsí y traza una superioridad espiritual sobre la temporal, la cual se explicará por la diferencia entre las leyes veterotestamentarias y las "nuevas". De este modo, invierte el orden que intenta plasmar Alfonso en su ley con la glosa ad verbum "politica". Allí, da por cierta la información otorgada por el rey Sabio, pero establece la necesidad de entender que el Dios verdadero se expresó en la ley de Cristo y, bajo esa ley, el sacerdocio está por arriba del laico. Como puede verse, aun en medio de una seguidilla de aprobación, en todos aquellos espacios en donde Alfonso plantea una dialéctica del orden atacando o limitando al poder espiritual, López establece una contradicción. En su glosa, de hecho, destaca que es válido pensar ese poder tremendo del rey a imitación de Dios, pero no para las cosas espirituales. Esto es otra prueba de la dinámica descripta.

Si bien al principio de la segunda Partida los redactores plantearon una homogeneidad entre la figura del rey y la del emperador, en la ley séptima comienza a esbozarse una idea que se tornará fuerte y clara a lo largo de toda esa Partida:

Complidas e verdaderas razones mostraron los sabios antiguos porque conuino que fuese Rey, mas de aquellas que de suso diximos del emperador. E como quier que ante fablamos del por la honrra del imperio, que del Rey, pero antiguamente, primero fueron los Reyes que los emperadores [...] los vnos quieren mas valer que los otros. E por ende fue menester por derecha fuerça que ouiessse vno que fuesse cabeça dellos, por cuyo seso se acordassem e se guiasen assi como todos los miembros del cuerpo se guian e se mandan por la cabeça. E por esta razon conuino que fuessen los reyes e los tomassen los omes por señores. E otra razón ya spiritual segun dicho de los profetas e de los santos porque fueron los Reyes e es esta que la justicia que nuestro señor Dios auia a dar en el mundo, porque biuiessen los omes en paz e en amor, que ouiesse quien la fiziesse por el en las cosas temporales [...] E tiene el Rey lugar de Dios [...] en su reyno, $[\ldots]$ bien assi como de suso diximos que lo tiene el Emperador en el imperio. E aun de mas que el Rey lo tiene por heredamiento, e el Emperador por elección.

Este pasaje viene a profundizar al anterior, pues replantea la historicidad como elemento veraz que hace a la construcción de ese poder monárquico. Sin embargo, este párrafo, quizá como ningún otro, contiene el núcleo del razonamiento alfonsí. De tal modo, el planteo por el cual coloca en un lugar superior al rey con respecto al emperador es el mismo tipo de razonamiento por el cual quería plantear esa superioridad sobre los religiosos, la tan ponderada historia primigenia de su creación como querida por Dios, siendo él mismo rey, y considerando que es la mejor forma de gobernar la tierra con el objetivo de establecer en ella la justicia necesaria para llegar a esa salvación tan requerida (expuesta como razón para considerar superior a lo espiritual en la glosa recién citada de López). Esta misma razón "datada" históricamente, le da ese carácter de espiritual al poder del rey en la medida en que es puesto por 
Dios de modo directo y, a partir de allí, se produce ese salto hacia considerar al rey como Dios en su reino, como aquél que tiene su lugar. No es casual que esa acepción del vicario de Dios se establece en años previos y cercanos a la sistematización del concepto político papal de vicario de Cristo ${ }^{42}$. Cierra esa argumentación planteando la superioridad del rey por vía del origen de su potestad.

En la siguiente ley observa que:

Sabida cosa es que todos aquellos poderes que de suso diximos que los Emperadores han e deuen auer en las gentes de su imperio, que essos mismos han los Reyes en las de sus reynos e mayores. Ca ellos non tan solamente son señores de sus tierras mientra biuen, mas aun a sus finamientos las pueden dexar a sus herederos, porque han el sennorio por heredad [...] Otrosi dezimos que el rey se puede seruir e ayudar de las gentes del reyno, quando le fuere menester, [...] que lo non podria fazer el emperador. Ca el por ninguna cuyta que le venga non puede apremiar a los del imperio que le den mas de aquello que antiguamente fue acostumbrado de dar a los otros emperadores [...] Mas el Rey puede demandar e tomar del reyno lo que vsaron los otros Reyes que fueron ante que el e aun mas $[\ldots]$

Por último, en la glosa ad verbum "quisiere" $(P$. II, I, 8), Gregorio López va en contra de una visión patrimonial del reino en favor de una ligada al territorio como entidad coherente e indivisible. De este modo, el comentador plantea que el rey debe, en todo caso, aumentar el reino, jamás cortarlo. Aun en casos donde pudiera otorgar derechos sobre territorios, cosa que no puede hacer el emperador, cuando dicha donación aunque basada en la "suprema potestate, donare non posset". Entonces, aun sosteniendo esa superioridad y admitiendo esa extrema y absoluta capacidad del rey, ya existe un principio necesario en la definición de territorio que se liga a una idea coherente de reino como espacio vital de los habitantes.

Como cierre, volvemos sobre un elemento de suma importancia, el del vicariato. El rey Sabio explicitará que:

Vicarios de Dios son los Reyes cada vno en su reyno, puestos sobre las gentes para mantenerlas en justicia e en verdad quanto en lo temporal, bien assi como el Emperador en su imperio. Esto se demuestra complidamente en dos maneras. La primera dellas es spiritual, segund lo mostraron los profetas e los santos aquien dio nuestro señor gracia de saberlas cosas ciertamente e de fazerlas entender. La otra segund natura, assi como mostraron los omes sabios que fueron conoscedores delas cosas naturalmente. E dixeron los santos que el Rey es puesto en la tierra en lugar de Dios para complir la justicia e dar cada vno su derecho. E porende lo llamaron coraçon e alma del pueblo. Ca assi como

\footnotetext{
${ }^{42}$ Michael Wilks, "Papa est nomen iurisdictionis: Augustinus Triumphus and the papal vicariate of Christ”, Journal of Theological Studies, 8, 1957, pp. 256-271.
} 
yaze el alma en el coraçon del ome e por ella biue el cuerpo e se mantiene, assi en el Rey yaze la justicia que es vida e mantenimiento del pueblo de su sennorio. E bien otrosi como el coraçon es vno e por el reciben todos los otros miembros vnidad para ser vn cuerpo, bien assi todos los del reyno maguer sean muchos (porque el Rey es e deue ser vno) por esso deuen otrosi ser todos vnos con el, para servirle e ayudarle en las cosas que el ha de fazer. E naturalmente dixeron los sabios que el Rey es cabeça del reyno, ca assi como de la cabeça nascen los sentidos, porque se mandan todos los miembros del cuerpo, bien assi por el mandamiento que nasce del Rey, que es señor e cabeça de todos los del reyno, se deuen mandar e guiar e auer vn acuerdo con el para obedescerle e amparar, e guardar, e acresecentar el reyno. Onde el es alma e cabeça e ellos miembros. (P. II, I, 5).

El concepto de vicario de Dios, definitivamente, no ocupa un lugar intuitivo ni vacío. En Partidas el papa siempre es vicario de Cristo, a la vez que el rey siempre es vicario de Dios. Esta noción implica su postulación dentro de un registro conceptual conflictivo de su época. La expresión de poder en el espacio interior es reafirmada por medio de la construcción vicarial y muestra, de hecho, el fundamento religioso que no niega, sino que sostiene como principio de legitimidad del monarca. De tal modo, aparece un paralelismo que resume todo lo dicho: este poder se expresa como la idea del rey en tanto vicario de Dios, pero este poder expresado con tintes religiosos tiene un campo de aplicación específico “en lo temporal”. Por eso, Alfonso realiza el planteo del concepto, le adscribe su esfera de acción y, luego, coloca su primer fundamento: lo espiritual. Esta pretensión de absoluta superioridad es construida a través de un concepto político de origen religioso. Así, lo espiritual se presenta como el origen de ese poder exigido, contrastante y conformador de dinámicas de expresión soberana.

La complejidad y la extensión de los temas tratados no pueden sino impedirnos cualquier pretensión de conclusiones abarcadoras o uniformizadoras. En ese sentido, la falta de un vocabulario adecuado en la Edad Media para nombrar los conceptos analizados nos movilizó a buscar los sentidos entre las definiciones de otras cosas. Principalmente, de aquellas en las que se juegan las relaciones de poder. El derecho, en este sentido, es el caldo de cultivo, en tanto escenario renovador y constructor de legitimidad, para condensar pretensiones que se gestaban en otros espacios.

\section{Conclusiones}

La realidad material diversa de estos contextos de escritura explica buena parte de las diferencias. Sin embargo, entendemos que el siglo XIII, emergido al calor de férreos debates filosófico-teológicos, desarrolla una idea en crecimiento de soberanía. A partir de esto se explica la labor legislativa alfonsí, la cual legisla sobre toda materia constituyente de la vida social y regula hasta aquello que debería pertenecer a otra 
esfera de acción. A su vez, planteamos que esto no supone una intromisión del poder temporal en el espiritual, marcos que el Sabio rey respeta con ahínco, sino que plantea el nacimiento de algo nuevo. El discurso alfonsí admite una fuente y un destino ligado al bien común y al pueblo, que está ligado a la tierra. El problema no es el del reparto de poderes, sino el del nacimiento de una nueva entidad que regule la vida social por entero. Aunque lo usa de modo contradictorio por momentos, el derecho dará a Alfonso la herramienta para forjar una sociedad subsumida al $i u s^{43}$. Aunque su coyuntura fuera marcada por el fracaso.

En contraposición, Gregorio López da muestras de un siglo XVI que se encuentra atravesado por conflictos dentro de España, así como en otros territorios imperiales. En este sentido, el glosador, con absoluta erudición, nos muestra un nuevo fracaso: el del modelo carolino. Esa presencia de Partidas es síntoma de esa necesidad de volver a mirar a España, una España que está mirando América. A nuestro juicio esto es lo que explica algunas de las diferencias. A su vez, y para terminar, debemos dejar asentado que estas diferencias no marcan excepcionalidad, sino los saltos y contradicciones que puedan plantearse en cualquier proceso de construcción a largo plazo. Estas incompatibilidades, una vez más, nos permiten entender las características históricas específicas de cada contexto sin perdernos en una imposible dinámica homogeneizante de construcción del Estado Moderno en el Occidente medieval.

\footnotetext{
${ }^{43}$ Georges Martin, "Le concept de 'Naturalité' dans les Sept Parties d'Alphonse X le Sage", Construir la identidad en la Edad Media. Poder y memoria en la Castilla de los siglos VII a XV, Cuenca, 2010, pp. 145-163.
} 


\section{Anexos}

2) Prólogo de la versión legalista

(A)

A Dios deue omne adelantar et poner primeramiente en todos los buenos fechos que quisiere començar. $\mathrm{Ca}$ el es comienço et fazedor e acabamiento de todo bien ${ }^{44}$. Por ende ${ }^{45}$ nos, don Alfonso, fijo del muy noble rey don Fernando et de la muy noble reyna doña Beatriz, regnando en Castiella, en Toledo, en Leon, en Gallizia, en Sevilla, en Cordova, en Murcia, en Jahen et en el Algarbe ${ }^{46}$, començamos este libro en el nombre del padre et del fijo et del spiritu sancto que son tres personas et un Dios verdadero, et deçimos asi. Porque las voluntades et los entendimientos de los omnes son departidos en muchas maneras, por ende los fechos et las obras dellos no acuerdan en uno, et desto nascen grandes contiendas et muchos otros males por las tierras. Porque conviene a los reyes que han a tener et a guardar sus pueblos en paz et en iustitcia, que fagan leyes et posturas et fueros, porque el desacuerdo que han los omnes naturalmientre entre si se acuerde por fuerça de derecho, asi que los buenos vivan bien et en paz, et los malos sean escarmentados de sus maldades. E por ende nos, el sobredicho rey don Alfonso, entendiendo et veyendo ${ }^{47}$ los grandes males que nascen et se levantan entre las gentes de nuestro señorio por los muchos fueros que usavan en las villas et en las tierras, que eran contra Dios et contra derecho; asi que los unos se judgava por fazannas desaguisadas et sin razon, et los otros por libros minguados de derecho, et aun aquellos libros rayen ${ }^{48}$ e escrivien $\mathrm{ya}^{49}$ lo que les semeiava a pro dellos et a daño de los pueblos, tolliendo a los reyes su poderio $\mathrm{y}$ sus derechos et tomandolo pora $\mathrm{si}^{50}$ por lo que non deue ser fecho en ninguna manera. Et

${ }^{44} \mathrm{HC}$ omite "adelantar et poner en todos los buenos fechos".

${ }^{45} \mathrm{HC}, \mathrm{X}-131$ y Biblio. Real $3^{\circ}$ agregan "Et por ende...".

${ }^{46} \mathrm{HC}$ y Biblio. Real $3^{\circ}$ agregan "et" en cada elemento de la parataxis.

${ }^{47} \mathrm{HC}$ omite "et veyendo".

${ }^{48}$ MB "rayen", al igual que X-131, pero HC parecería colocar "trayen", aunque la mancha ubicada justo allí no me permite ver si es duplicación ("rrayen") o agregado de otra letra ("trayen"). Aunque lo lógico sería suponer duplicación, el astil superior inicial me indica una "t". El único sentido que podría hallarle a esa variante es que el copista quisiera corregir una palabra que en su tiempo no gozaba de mucho uso ya a fines del siglo XIV y quiera referir al verbo traer, que en latín es trahěre y esa hache intermedia (que evidentemente no posee valor de vocal a pesar del diptongo) normalmente en castellano medieval sonaría (por comparación gramatical) aproximadamente como una fricativa alveopalatal sorda. Por lo tanto, volviendo al sentido, parecería haber querido decir que los libros referidos "traen a tema" cuestiones no convenientes al derecho, etc. Pero carece de mayor importancia. Dejando de lado entonces este error, me interesa destacar esta preocupación material que aparece en el texto alfonsí por la conservación de los libros de derecho. Ese "rayen" viene, naturalmente, del verbo "radere" y se refiere a la acción de borrar del pergamino. Esta preocupación por la cesación de crear palimpsestos resulta de extrema importancia para la concepción jurídica alfonsí en los términos en que la definimos en la primera parte de la tesis. Así, rey-libro-ley aparecen aquí como ese núcleo indisoluble que venimos sosteniendo.

${ }^{49} \mathrm{X}-131$ omite " $y a$ ".

${ }^{50}$ Biblio. Real $3^{\circ}$ dice “tomandolos para sí...”. Esta fórmula se encuentra también en X-131, los otros dos mss. dicen "tomandolo por asi...". Modificamos ambas y establecemos el "pora si" original que tiene valor de "para si". Refiere a la acción de enajenar los textos jurídicos y cambiarles la letra haciendo que digan aquello que era conveniente para quien lo hacía. Una vez más se destaca el aspecto material 
por todas estas razones minguavase la iusticia et el derecho por que los que avien judgar los pleytos non podien en cierto ni conplidamiente dar los juidzios, ante los davan a ventura et a su voluntad, et los que recibien el daño non podien aver iusticia ni enmienda asi cuemo devien. Onde nos, por toller todos estos males que dicho avemos, fiziemos estas leyes que son escriptas en este libro a servicio de Dios et a pro comunal de todos los de nuestro señorio, por que conoscan et entiendan ciertamientre el derecho et sepan obrar por el et guardarse de fazer yerro porque no cayan en pena. Et tomamoslas de los buenos fueros et de las buenas costumbres de Castiella et de Leon et del derecho que fallamos que es mas comunal et mas provechoso $^{51}$ para las gentes en todo el mundo. Porque tenemos por bien et mandamos que se yudguen $^{52}$ por ellas et no por otra ley ni por otro fuero. Onde qui contra esto fiziesse dezimos que errarie en tres maneras. La primera, contra Dios, cuya es complidamientre la iusticia et la verdat porque este libro es fecho. La segunda, contra señor natural, despreciando su fecho et su mandamiento. La tercera, mostrandose por sobervio et por torticero, nol plaziendo el derecho connosçudo et provechoso comunalmientre a todos ${ }^{53}$.

que cierra la idea que se abrió con el "rayen" en los libros de derecho. Iglesia Ferreirós (1996) plantea que esta práctica era muy común en los momentos de conflicto judicial, y que los señores particulares hacían uso extendido de ella para hacer coincidir texto el texto del rey con sus pretensiones. Como vemos, en este pequeño detalle, hay todo un caso de conflicto por las formas del ejercicio del poder.

${ }^{51} \mathrm{HC}$ omite el primer "mas".

${ }^{52}$ Biblio. Real $3^{\circ}$ cambia por "gobiernen".

${ }^{53}$ Esc. $1^{\circ}, 2^{\circ}$ y Biblio. Real $2^{\circ}$ agregan "Et por ende, deve rescebir tal pena de la manera que la diere o quisiere dar el señor cuyo señorio despreçio". 
3) Prologo de la versión sapiencial

Dios es comienç $0^{54}$ et medio ${ }^{55}$ et $^{56}$ acabamiento de todas las cosas del mundo ${ }^{57}$, et sin el ninguna ${ }^{58}$ non puede ser $\uparrow$ Ca por el su saber son fechas et por el su poder son governadas et por la su bondad son mantenidas ${ }^{59}$ Onde todo ombre que algun buen fecho quisiere ${ }^{60}$ començar, primero deve poner et adelantar a Dios en el, rogandole et pidiendole mercet ${ }^{61}$ et le de saber et voluntad et poder $^{62}$ para que lo pueda bien acabar $\$ Por ende nos, don Alfonso, por la gracia de Dios rey de Castilla, et de Toledo, et de Leon, et de Galizia, et de Sevilla, et de Cordova et de Murcia, et de Jahen, et del Algarbe ${ }^{63}$, entendiendo ${ }^{64}$ los grandes ${ }^{65}$ logares que tienen de Dios los reyes en el mundo et los bienes que del resciben en muchas maneras et señaladamente en la muy grand onrra ${ }^{66}$ que les faze queriendo que sean llamados reyes que es el su nombre E otrosi por la iustiçia que han de fazer para mantener los pueblos de que son señores que es la su obra ${ }^{67}$ E conosciendo la muy grand carga ${ }^{68}$ que les yace $^{69}$ en esto, que si bien non lo fizieren, non tan solamente por el miedo de Dios que es poderoso et justiciero, a cuyo juyzio han de venir et a que non se pueden por ninguna manera esconder nin escusar $^{70}$ que si mal fiçieron non resciban la pena que merescen $\$ Mas aun, por la verguença et afruenta $^{71}$ de las gentes del mundo que juzgan las cosas mas por voluntad que por derecho $\emptyset$ E aviendo nos grand sabor ${ }^{72}$ de nos guardar destas $\operatorname{dos}^{73}$ afruentas ${ }^{74}$ et del daño que por ellas nos podria venir, et catando otrosi la muy grant mercet que Dios nos fizo en querer que vinie-

\footnotetext{
${ }^{54}$ Biblio. Real $2^{\text {o: }}$ "començamiento".

${ }^{55}$ Tol. $1^{\circ}$ y $2^{\circ}$ y Biblio. Real $2^{\circ}$ "medianero"; Tol. $3^{\circ}$ y Esc. $1^{\circ}$ y $2^{\circ}$ "medianeria"; ms. 12.793 "mediania".

${ }^{56}$ Ms. 12.793 agrega “... fin et...”.

${ }^{57}$ Tol. $1^{\circ}, 2^{\circ}$ y $3^{\circ}$, Biblio. Real $2^{\circ}$, ms. 12793 , Esc. $1^{\circ}$ y $2^{\circ}$, omiten “del mundo".

${ }^{58}$ Tol. $1^{\circ}$ y $2^{\circ}$, Biblio. Real $2^{\circ}$, y Esc. $2^{\circ}$ agregan "ninguna cosa non puede ser". ms. 12.793 agregan "sin el cosa alguna non puede ser".

${ }^{59}$ Tol. $1^{\circ}$ “... et por el su saber começadas"; Tol. $3^{\circ}$ "por el su poder son fechas, por el su saber governadas"; Biblio. Real $2^{\circ}$ omite el "fazer" y expone "Et por el su saber governadas et por la su bondat mantenidas"; ms. 12.793 “... saber son fechas et por el su poder guardadas... ”; Esc. $1^{\circ}$ y $2^{\circ}$ “... poder son fechas et por el su poder governadas..."; Vitr. 4-6 “... por el su nombre son fechas et por el su poderio son criadas et governadas...". (En cuanto al porqué de la elección crítica, ver nota 140)

${ }^{60}$ Vitr. 4-6 "oviere de".

${ }^{61}$ Vitr. 4-6 agrega "le ayude".

${ }^{62}$ Vitr. 4-6 "poderio".

${ }^{63}$ Vitr. 4-6 y ms. 12.793 omiten posesiones y colocan "et etc." luego de nombrar Castilla y León.

${ }^{64}$ Vitr. 4-6 agrega "et veyendo".

${ }^{65}$ Ms. 12793 agregan "muy".

${ }^{66}$ Vitr. 4-6 "loor".

${ }^{67}$ Esc. $1^{\circ}$ omite "que es la su obra".

${ }^{68}$ Ms. 12.793 "la carga muy grande".

${ }^{69}$ Vitr. 4-6 "nasce".

${ }^{70}$ Vitr. 4-6 "... non se puede escusar nin por ninguna manera esconder nin desuyar...".

${ }^{71}$ Esc. $2^{\mathrm{o}}$ "afrenta"; ms. 12.793, Sil. y Tol. $1^{\circ}$ "afruento"; Tol. $2^{\circ}$ y $3^{\circ}$ "afrontamiento".

${ }^{72}$ Vitr. 4-6 "voluntad".

${ }^{73}$ Tol. $3^{\circ}$, ms. 12.793 y Sil. omiten "dos".

${ }^{74}$ Tol. $2^{\circ}$ y $3^{\circ}$ y ms. 12793 cambian el uso del singular al plural: Tol. $2^{\circ}$ y $3^{\circ}$ usan "afruentos" y ms. 12.793 "afruentas".
} 
semos del linage onde venimos et el grand logar en que nos el puso faziendo nos señor de tantas buenas gentes et de tan grandes tierras ${ }^{75}$ como el quiso meter so nuestro señorio, cataremos carreras por que nos et los que despues de nos en nuestro señorio regnaren sepan los derechos para mantener los pueblos en justiçia et en paz $\mathbb{E}$ otrosi, porque los entendimientos de los ombres son ${ }^{76}$ departidos en muchas maneras, pudiessen acordar en uno con razon verdadera et derecha para conoscer primeramente a Dios, cuyos son los cuerpos et las animas, que es señor sobre todos, et de si a los señores temporales de quien resciben bien fecho en estas maneras cada uno en su estado segunt su merescimiento ${ }^{77}$ - E otrosi, porque fiziesen aquellas cosas que fuesen tenidos por buenas de que les pudiesse venir bien et se guardasen de fazer yerro que les estuviese mal et de que les pudiesse venir daño por su culpa ${ }^{78} \mathbb{E}$ E porque todas estas cosas non podrian fazer los ombres complidamente si non conosciesen ${ }^{79}$ cada uno $^{\circ}$ su estado qual es, et lo que conviene que faga en el et de lo que se deve guardar, ${ }^{80}$ et otrosi de $\operatorname{los}^{81}$ estados de las otras cosas a que deven obedescer ${ }^{82}$ E por eso fablamos de todas las ${ }^{83}$ razones $^{84}$ que a esto pertenescen $\llbracket$ Fiziemos ende este libro ${ }^{85}$ porque nos ayudasemos del et los

${ }^{75}$ Ms. 12.793 "et regnos".

${ }^{76}$ A partir de aquí se lee el Sil.

${ }^{77}$ Biblio. Real $2^{\circ}$, Esc. $1^{\circ}$ y Tol. $3^{\circ}$ omiten "et su merescimiento" y agregan "et el debdo que an con ellos".

${ }^{78}$ Biblio. Real $2^{\circ}$ y Esc. $1^{0}$ "merescimiento".

${ }^{79}$ Aquí el Sil. se hace ilegible.

${ }^{80}$ A partir de aquí Esc. $1^{\circ}$ y $2^{\circ}$ cambian de texto (tal y como indicamos en la leyenda del cuadro 1). "fiziemos este libro porque pudiesen mejor entender estas cosas sobredichas et obrar por ellas segunt conviene $\uparrow$ Et teniendo que el nuestro entendimiento et el nuestro seso non podria esto conplir acordamos en esta obra primeramente de los mandamientos et de los castigos que dios dixo et mando 9 Et otrosi de los sanctos que fueron sus amigos et mostraron spiritualmente la su virtud et la su salvaçion de las gentes T Et otrosi tomamos de las buenas palabras et de los buenos consejos que dixeron los sabios que entendieron las cosas razonablemente segunt natura $\uparrow$ Et de los derechos et de las leyes et de los buenos fueros que fizieron los grandes señores et los sabios antiguos por el mundo $\uparrow$ Et por todas estas razones touvimos por bien et mandamos que todos los de nuestro señorio reçiban este libro [aquí comienza la versión A incrustada] et se judgen por el et non por otras leyes nin por otro fuero et quien non lo quisiere rescebir dezimos que errarie en estas maneras $\uparrow$ La primera contra dios cuya es complidamente la justicia et la verdat $\uparrow$ la segunda* mostrandose por sobervio et torticero nos plaziendo del derecho que es conoscido provechoso et comunalmente a todos 9 Et por ende deve rescebir tal pena qual manera que la quisiere dar el señor cuyo señorio despreçio Por quales razones este libro es partido en Siete partes".

* en esa parte hay un error de copia donde el amanuense debe haber salteado una línea, ya que copia como segunda, la tercera razón y luego falta dicha tercera. Esto en Esc. $1^{\circ}$, que fue el que seguimos para esta nota, en Esc. $2^{\circ}$ hay una llamada con la leyenda al costado que colocaría en ese espacio la segunda razon "contra señor natural, despreciando su fecho et su mandamiento" y agrega "La tercera...".

${ }^{81}$ Aquí vuelve a leerse el Sil.

${ }^{82}$ Variantes: Tol. $2^{\circ}$ intercala una copia de la misma línea previa "que fiçiesse aquellas cosas por que fuessen tenudas et de quales viniesse bien et se guardasen de fazer yerros de quales estuviesen mal et quales pudiese venir daño por su culpa".

${ }^{83}$ Vitr. 4-6 agrega "otras".

${ }^{84}$ Ms. 12.793 "cosas".

${ }^{85} \mathrm{Tol} .1^{\circ}$ se corta con respecto a los otros testimonios (el amanuense aquí salteó un párrafo entero) y prosigue uniendo con "et porque las nuestras gentes son leales et de grandes coraçones..."; Biblio. Real $2^{\circ}$ escribe " $\ldots$ a pro et a onrra de los omes de nuestro señorio et de todos los otros que por el quisieren 
otros que despues de nos vinieren, conosciendo las $\operatorname{cosas}^{86}$ et yendo a ellas ciertamente $9 \mathrm{Ca}$ mucho conviene a los reyes, et señaladamente a los de esta tierra, ${ }^{87}$ conoscer las cosas según son et estremar el derecho del tuerto et la mentira de la verdat $\uparrow \mathrm{Ca}$ el que esto non sopiere non podrie fazer la justiçia bien et complidamente ${ }^{88}$ que es dar a cada uno lo que le conviene et lo que meresce 1 E por que las nuestras gentes son ${ }^{89}$ leales et de grandes coraçones, por eso es menester que la lealtad se mantenga con la verdat et la fortaleza de las voluntades con derecho ${ }^{90}$ et justiçia $\int \mathrm{Ca} \operatorname{los}^{91}$ reyes sabiendo las cosas que ${ }^{92}$ son verdaderas et derechas ${ }^{93}$ fazer las han ellos et non consintan a los otros que pasen ${ }^{94}$ contra ellas ${ }^{95}$ según dixo el rey Salomon que fue muy sabio et muy ${ }^{96}$ justiciero que quando el rey estoviere en su cathedra de justiçia que con el su catamiento se desaten todos los males, ca despues que lo entendiere guardara a si et a $\operatorname{los}{ }^{97}$ otros de daños ${ }^{98}$ E por esta razon fazemos señaladamente este libro, porque siempre los reyes de nuestro señorio ${ }^{99}$ se caten siempre en el asi como en espeio et vean las cosas que han de emendar ${ }^{100}$ en si et las enmienden et según aquesto que fagan en los suyos ${ }^{101}$ Mas porque, tantas razones nin tan buenas como avie menester para mostrar ${ }^{102}$ este fecho non podriemos nos fablar ${ }^{103}$ por nuestro seso nin por nuestro entendimiento, ${ }^{104}$ para complir ${ }^{105} \tan$

obrar, porque meior puedan entender esto sobredicho et obrar por ello segund conviene. Et señaladamente a los reys desta tierra que an de aver muy grand entendimiento para poder bien mantener sus gentes en verdat et con Iusticia. Ca esta son dos cosas porque la alçan los que la fazen en este mundo et en el otro, porque son apreciados et amados et loados. Et en el otro regno escogidos et onrrados et acabados...".

${ }^{86}$ Sil. acorta y une "... segunt son et estremar el derecho del tuerto...". El amanuense se saltó, evidentemente, una línea.

${ }^{87}$ Tol. $3^{\circ}$ agrega “... de aver grande entendimiento para..."; ms. 12793 “... de aver muy grand entendimiento para...”.

${ }^{88}$ Ms. 12793 reemplaza por "verdaderamente".

${ }^{89}$ Ms. 12793 agrega "muy".

${ }^{90}$ Biblio. Real $2^{\circ}$ omite "derecho".

${ }^{91}$ Aquí el Sil. vuelve a tornarse ilegible.

92 Vitr. 4-6 "quales".

${ }^{93}$ Tol. $1^{\circ}$ omite "derechas".

${ }^{94}$ Tol. 1 " "fazen".

${ }^{95}$ Aquí vuelve a leerse el Sil.

${ }^{96}$ Vitr. 4-6 omite "muy".

${ }^{97}$ Sil. “... regnos de nuestro señorio et se caten en el asi como en espeio...”. Nuevamente se salteó una línea. Esta omisión, sin embargo, muestra un arreglo, ya que el texto es coherente y "arregla" las faltas con coordinantes, etc. Por lo tanto, deberíamos considerar que es copia de un texto distinto que omitió y el amanuense arregló la evidente omisión que ya tenía. De otro modo, no tiene sentido pensar en que el mismo que omite arregle problemas de cohesión textual provocados por la omisión.

${ }^{98}$ Biblio. Real $2^{\text {o } ~ “ . . . ~ g u a r d e ~ d e ~ d a n ̃ o ~ a ~ l o s ~ o t r o s, ~ l o ~ q u e ~ e s ~ m e n e s t e r ~ a ~ l o s ~ r e y e s ~ d e ~ n u e s t r o ~ s e n ̃ o r i o ~ q u e ~}$ sepan bien ciertamente el derecho para que sean ellos bien guardados et puedan guardar a los otros. Et por ende...".

${ }^{99}$ Tol. $2^{\circ}$ omite "de nuestro señorio".

${ }^{100}$ Sil. omite "en si et las enmienden et según aquesto que".

${ }^{101}$ Tol. $1^{\circ}$ “... que fagan esso en sus pueblos"; Esc. $3^{\circ}$ “... que fagan aquesto que fazen en las sus gentes".

${ }^{102}$ Tol. $2^{\circ}$ omite "para mostrar".

${ }^{103}$ Tol. $1^{\circ}$ agrega “... en los sus pueblos... ”; Sil. reemplaza por "mostrar".

${ }^{104}$ Sil. invierte "entendimiento nin por nuestro seso".

${ }^{105}$ Ms. 12.793 agrega “... et acabar”. 
grand obra et tan buena como esta, acorriemos nos de la mercet ${ }^{106}$ de Dios et del su fijo bendito nuestro señor Jesucristo en cuyo nombre ${ }^{107}$ nos los començamos, ${ }^{108}$ et de la virgen ${ }^{109}$ santa Maria su madre que es medianera entre nos et ${ }^{110}$ toda la su corte celestial ${ }^{111}$ E otrosi, de los buenos $^{112}$ dichos dellos ${ }^{113}$ I E otrosi ${ }^{114}$ tomamos $^{115}$ de las palabras et de los buenos dichos ${ }^{116}$ que dixeron los sabios que entendieron las cosas razonablemente ${ }^{117}$ segun natura, et de $\operatorname{los}^{118}$ derechos et de las ${ }^{119}$ leyes et de los buenos fueros que fizieron los grandes señores et los otros ombres ${ }^{120}$ sabidores en derecho en las tierras que ovieron de juzgar. Et pusiemos cada una destas razones $^{121}$ do convien ${ }^{122}$ E E a esto nos movieron ${ }^{123}$ señaladamente tres razones ${ }^{124} \uparrow \mathrm{La}$

${ }^{106}$ Ms. 12.793 "virtud".

${ }^{107}$ Tol. $3^{\circ}$. El resto coloca "esfuerço". El copista tomó la palabra de unas líneas más abajo al perder la lectura. Este error resulta significativo.

${ }^{108}$ Tol. $1^{\circ}$ "encomendamos".

${ }^{109}$ Tol. $1^{\circ}$ “... bienaventurada santa María”; ms. 12.793 “... bienaventurada virgen gloriosa santa María”. ${ }^{110}$ Tol. $2^{\circ}$ y $3^{\circ}$ y ms. 12.793 y Sil. “... et el”.

${ }^{111}$ Biblio. Real $2^{\circ}$ "mas, por tantas razones nin tan buenas como avien menester para este fecho, mostrar non podriamos nos, nin fallar para completar tan grand obra et tan buena como esta con nuestro entendimiento nin con nuestro seso. Por eso, con la merced de Dios en cuyo esfuerço nos lo començamos pidiendo merceed que nos guiase en ella a su servicio, en manera que a el ploguiese et que nos le pudiesemos dar buena cuenta del lugar que tenemos et de los muchos bienes et mercedes que deste abiemos, primeramente de los mandamientos et de los castigos que dixo et el mando, otrosi de los sanctos que fueron sus amigos et mostraron spiritualmente la su verdat et la salvacion de las gentes, et otrosi tomamos de las buenas palabras et de los buenos dichos que dixeron los sabios, que entendieron las cosas razonablemente segund natura, de los derechos et de las leyes et de los buenos fueros que fizieron los grandes señores et los otros omes sabidores de derecho en las tierras que ovieron de judgar. Et pusimos cada una destas razones do conviene et porque pedimos merced a Dios, que el la entierre et meta en corazon a los que la oyeren, que la entiendan complidamente segund es et ayan plazer con ella et la reciban. Et rogamos a los reyes que regnaren despues de nosotros en nuestro logar, que la tengan en caro et que la guarden por su pro et por su onrra, et a todos los otros que la amen por su bien et por su guarda $q \mathrm{Et}$ los que esto non quisieren fazer errarien en tres maneras. La primera, contra Dios, cuya es complidamente la justicia et la verdat. La segunda, contra señor natural, despreciando sus fechos et mandamientos $\uparrow \mathrm{La}$ tercera, mostrandose por soberbios et por torticeros, non le plaziendo el derecho que es conocidoet puesto so contrariamente a todos. Et sin la pena que Dios les darie por ello, tenemos que deven aun tamaña pena como se la quisiere dar el señor cuyo señorio despreciaron. Por quales razones este libro es partido en siete partes.

${ }^{112}$ Tol. $2^{\circ}$ y $3^{\circ}$, Esc. $3^{\circ}$ y ms. 12.793 y Sil. omiten "buenos".

${ }^{113}$ Tol. $1^{\circ}$ "E otrosi, de los derechos de ellos"; Esc. $3^{\circ}$ "E otrosi, tomamos de lso dichos et de los vienes et mercedes que del tenemos primeramente, de los mandamientos et de los castigos que eldixo et mando"; Vitr. 4-6 "E otrosi, de los buenos dichos et mercedesque del rescebimos, primeramente de los mandamientos et castigos que del rescebimos et dexo et mando".

${ }^{114}$ Tol. $2^{\circ}$ y $3^{\circ}$ y ms. 12.793 "Et tomamos [catamos] de las palabras et de las buenas raçones..."; Sil. "et tomamos de las buenas palabras et de las buenas razones...".

${ }^{115}$ Tol. $2^{\circ}$ "catamos".

${ }^{116}$ Tol. $2^{\circ}$ y $3^{\circ}$ y ms. 12.793 y Sil. "razones".

${ }^{117}$ Vitr. 4-6 "como en razon".

${ }^{118}$ Ms. 12.793 "et de los otros dichos de...".

119 Tol. $2^{\circ}$ “... todas...".

${ }^{120}$ Ms. 12.793 omite "ombres".

${ }^{121}$ Ms. 12.793 omite "razones". 
primera, que el muy noble et bien aventurado rey don Fernando, nuestro padre, que era complido de justicia et de derecho ${ }^{125}$, lo quisiera fazer si mas visviera, et mando a nos que lo fiziesemos ๆ La segunda, por dar esfuerço et ayuda ${ }^{126}$ a los que despues de $\operatorname{nos}^{127}$ regnasen, porque pudiesen mejor ${ }^{128}$ sofrir la grant ${ }^{129}$ lazeria et los trabajos que han de mantener ${ }^{130}$ los regnos los que bien lo han de fazer $\uparrow$ La tercera, por dar carrera a los ombres para conoscer derecho et razon ${ }^{131}$ et se sopiesen guardar ${ }^{132}$ de non fazer ningun tuerto ${ }^{133}$ et sopiesen amar et obedescer a los otros ${ }^{134}$ señores que despues dellos viniesen ${ }^{135}$ 的 este libro fue començado a componer et a fazer [en la] viespera de san Iohan Bautista en quatro años et veinte et tres dias $^{136}$ andados del comienço ${ }^{137}$ de nuestro regnado que començo quando andava la era de Adam en cinco mil et honze años hebraicos et ochenta et siete dias mas ${ }^{138}$ E la era del diluvio en quatro mill et trezientos et cinquenta et tres años romanos et ciento et cinco dias mas $₫ \mathrm{E}$ la era de Nabugodonosor en mill et nuevescientos et noventa et ocho años romanos et noventa et seys dias mas $\llbracket$ E la era de Felipo el grande rey de grecia en mill et quinientos et setenta et quatro años romanos et veynte et dos dias mas ${ }^{138}$ E la era del grand Alexandre de macedonia en mill et quinietos et setenta et dos años romanos et dozientos et quarenta dias mas $\$ E la era de Cesar en mill et dozientos et ochenta et nueve años romanos et ciento et cinquenta ${ }^{140}$ et dos dias mas $\mid$ E la era de la Encarnacion en mill et dozientos et cinquenta et un años romanos et ciento et cinquenta et dos dias mas $\mathbb{E}$ la era de Daciano el egipciano en nuevecientos et setenta et siete años romanos et dozientos et setenta et dos dias mas 9 E la era de los los aravigos en seyscientos et veynte et nueve años romanos et treçientos et veynte et un dia mas, segund los años dellos seyscientos et quarenta et nueve años et ochenta dias mas $\left\lceil\mathrm{E}^{141}\right.$ la era de los antigos en dozientos et veynte et nueve años romanos et dozientos et veynte et un dias

\footnotetext{
${ }^{122}$ Hasta acá llega el prólogo de Tol. $1^{\circ}$.

${ }^{123}$ Esc. $3^{\circ}$ "conviene", el resto utiliza "movio".

${ }^{124}$ Tol. $2^{\circ}, 3^{\circ}$ y Sil. "cosas".

${ }^{125}$ Ms. 12.793 "verdat".

${ }^{126}$ Esc. $3^{\circ}$, Tol. $2^{\circ}$ y $3^{\circ}$ y ms. 12793 "ayuda et esfuerço".

127 Tol. $2^{\circ}$ omite "de nos".

${ }^{128}$ Tol. $3^{\circ}$ omite "meior".

${ }^{129}$ Ms. 12.793 omite "grant".

${ }^{130}$ Esc. $3^{\circ}$ "las leys et".

${ }^{131}$ Tol. $2^{\circ}$ omite "et raçon".

${ }^{132}$ Sil. omite "de non fazer ningun".

${ }^{133}$ Esc. $3^{\circ}$ "algun tuerto"; Tol. $2^{\circ}$ y $3^{\circ}$ y ms. 12.793 y Sil. agregan "nin [o] yerro".

${ }^{134}$ Esc. $3^{\circ}$ "grandes".

${ }^{135}$ Esc. $3^{\circ}$ "tuviesen"; Tol. $2^{\circ}$ y $3^{\circ}$ y ms. 12.793 y Sil. pasan al singular y dicen “... pudiesen [sopiesen] amar et obedecer a los otros señores que despues de el viniesen".

${ }^{136}$ Vitr. 4-6 omite "et tres dias andados".

${ }^{137}$ Ms. 12.793 "comenzamiento".

${ }^{138}$ Vitr. 4-6 omite "mas".

${ }^{139}$ Vitr. 4-6 y Sil. omiten toda la lección; ms. 12.793 coloca "siete" en lugar de "dos" y omite “... quinientos et setenta et quatro...".

${ }^{140}$ Vitr. 4-6 "quarenta" (común error de copia, ya que las abreviaturas son muy parecidas).

${ }^{141}$ Sil. omite a partir de aquí todo hasta "Et segunt los años de los persianos...", y coloca posteriormente a la datación en era "araviga" el siguiente pasaje: "Et en otro logar dizen los omnes de los de XXLIX años et LXXX dias mas".
} 
mas E según los años debrios, seyscientos et nueve años romanos et ciento et ochenta dias mas E la era del rey Esdrae el persiano en seyscientos et diez et nueve años romanos et trezientos et quarenta et dos dias mas \ E según los años de los persianos, seyscientos et veynte años et ciento et quarenta dias mas $\llbracket \mathrm{E}$ fue acabado desque fue començado a siete años complidos. Por quantas razones es partido este libro en siete partes. 
Prólogo de Montalvo (1491)

A Dios deve home temer, servir et amar, porque ${ }^{142}$ Dios es comienço et medianero ${ }^{143}$ et acabamiento de todas las cosas, et sin el ninguna cosa puede ser. Ca por el su poder son fechas et por el su saber son governadas et por la su bondad son mantenidas, onde todo home que algun buen fecho quisiere començar primero deve poner et llamar ${ }^{144}$ a Dios en el rogandole et pidiendole merçed, que le de saber et voluntad et poder porque lo pueda bien acabar. Por ende, nos, don Alfonso, por la graçia de Dios Rey de Castilla, de Toledo, de Leon, de Galizia, de Sevilla, de Cordova, de Murcia, de Jahen, del Algarve, entendiendo los grandes logares que tienen de Dios los Reyes en el mundo et los bienes que del reçiben en muchas maneras, señaladamente en la muy grand honrra que les faze queriendo que ellos sean llamados reyes que es el su nome. E otrosi por la su justiçia que han de fazer para mantener los pueblos de que son señores, que es la su obra. E conoçiendo la muy grand carga que les yaze, que si lo non fiziessen, non tan solamente por el miedo de Dios, que es señor poderoso et justiçiero, a cuyo juyzio han a venir et de quien se non pueden por ninguna cosa asconder nin escusar, que si mal fizieren, non ayan la pena que meresçen, mas aun por la verguença et el afruenta de las gentes del mundo que judgan las cosas mas por voluntad que por derecho. Aviendo muy grand ${ }^{145}$ sabor de nos guardar destas dos ${ }^{146}$ afruentas et del daño que de ellas nos podie venir, e otrosi catando la muy gran merçed que nos fizo en querer que viniessemos del linaje onde venimos, et el gran logar en que nos puso faziendonos señor de tan buenas gentes et de tan grandes tierras como el quiso meter so nuestro señorio, catamos carreras porque nos et los que despues de nos regnassen el nuestro señorio sopiesemos çiertamente los derechos para mantener los pueblos en justiçia et en paz. Otrosi, porque los entendimientos de los homes que son departidos en muchas manetas podiessen acordarse en uno con razon verdadera et derecha para conocer primeramente a Dios cuyos son los cuerpos et las almas et es señor sobre todos et de si a los señores temporales de quien reçiben bien fecho en muchas maneras cada uno segund su estado et su mereçimiento. Otrosi que fiziesse aquellas cosas que fuesen tenudos por buenos et de que les viniese bien et se guardasen de fazer yerro que les estudiese mal et de que les pudiese venir daño por su culpa, et porque todas estas cosas non podrien fazer los homes complidamente si non conosçiese cada uno en su estado qual es, lo quel conviene quel faga en el et de lo que se deve guardar. E otrosi de los estados de las otras cosas a quien deven obedeçer. Por eso fablamos de todas las razones que a esto pertenescen et fezie-

\footnotetext{
${ }^{142}$ Esta lección es similar a la del comienzo de la versión legalista que versa: "A dios deue omne adelantar et poner primeramiente en todos los buenos fechos que quisiere començar".

${ }^{143}$ Esta variación, por demás adiáfora, la comparte con I, J y G.

${ }^{144}$ Esta variante resulta de interés. En primer lugar, porque no hay sinonimia; en segundo lugar, porque la elección de Montalvo no parece respetar el sentido de lo que intenta decir dicha invocación. Ningún testimonio mantiene esa forma. De cualquier manera, lo importante siempre a efectos de nuestras hipótesis se relaciona con el hecho de que si este texto hubiera sido el material de copia por parte de López, no podríamos tener hoy la diferencia que tenemos ya que es poco probable que Gregorio López (lo uso como si hubiera sido él quien realizó el acto mecánico de la copia) se equivocara, no siendo un error de copia habitual este cambio, y el resultado fuera aquello que figura en los manuscritos previos conservados.

${ }^{145} \mathrm{El}$ agregado del aumentativo parece un típico error por culpa del cajista, carece de valor.

${ }^{146}$ La implicancia de la ausencia en López de la referencia específica (que sí aparece en Montalvo) fue consignada ya en la cita 40 .
} 
mos ende este libro ${ }^{147}$. E porque las nuestras gentes son leales et de grandes coraçones, por esso han menester que la lealtad se mantenga con verdad et fortaleza de las voluntades con derecho et con justiçia. Ca los Reyes, sabiendo las cosas que son verdaderas et derechas fazerlas han como ellos et non consentiran a los otros que pasen contra ellas, segund dixo el Rey Salomon que fue sabio et muy justiciero, que quando el Rey soviere en su catedra de justiçia que ante el su acatamiento se desatan todos los males. Ca pues que los entendier guardara assi et a los otros de daño. E por esta razon fezimos señaladamente este libro, porque siempre los reyes de nuestro señorio se caten en el asi como en espejo et vean las cosas que han en si de emendar et las emienden et segund aquesto fagan en los sus pueblos ${ }^{148}$. Mas porque tantas razones nin tan buenas como avien menester para mostrar este fecho non podiamos nos fablar por nuestro entendimiento nin por nuestro seso, para complir tan grand obra et tan buena como esta acorrimonos de la merced de dios et del bendito su fijo nuestro señor jesu christo, en cuyo esfuerço nos lo començamos, et de la virgen santa maria su madre que es medianera entre nos et el et de toda la su corte celestial, et otrosi de los dichos de ella. E otrosi tomamos de las palabras et de los buenos dichos que dixeron los sabios que entendieron las cosas razonablemente segund natura, et de los derechos de las leyes et de los buenos fechos que fizieron los grandes señores et los otros homes sabidores de derecho en las tierras que ovieron de iudgar. Et posimos cada una destas razones do conviene. E a esto nos movieron señaladamente tres cosas: la primera, el muy noble et muy bien aventurado Rey don Fernando, nuestro padre, que era complido de justiçia et de derecho, que lo quisiera fazer si mas viviera et mando a nos que lo fiziesemos. La segunda, por dar ayuda et esfuerço a los que despues de nos regnassen, porque pudiessen mejor sofrir el grand trabajo que han de mantener los Reynos los que lo bien quisiesen fazer. La tercera, por dar esfuerço et carrera a los homes de conosçer el derecho et la razon et se sopiessen guardar de fazer tuerto nin yerro, et sopiesen amar et obedeçer a los otros señores que despues de nos viniessen. E este libro fue començado a componer bispera de san juan baptista a quatro años et veynte et tres dias andados del comienço del nuestro reynado, que començo quando andava la era de Adam en çinco mill et onze años et lxxxvii dias. E mas la era del diluvio en quatro mill et trezientos et cinquenta et tres años romanos et Xxv dias mas. E la era de nabugodonosor en mill et noveçientos et diez et ocho años romanos et noventa dias mas. E la era de felipo el grand Rey de greçia en mill et quinientos et setenta et quatro años romanos et veynte dos dias mas. E la era del grand alexandro de maçedonia en mill et quinientos et setenta et dos años romanos et dozientos et quarenta et tres dias. E la era de çesar en mill et dozientos et setenta et nueve años romanos et çiento et çincuenta dias mas. E la era de la encarnaçion en mill et dozientos et quarenta et un años romanos et çiento et çinquenta et dos dias mas. E la era de los aravigos en seysçientos et veynte et nueve años romanos et trezientos et veynte et un dia mas segund los años. E fue acavado desde que fue començado a siete años conplidos ${ }^{149}$.

\footnotetext{
${ }^{147}$ Aquí se produce una laguna con respecto a López y con respecto a todos los testimonios menos uno: I. ${ }_{148}$ Montalvo reemplaza "en los suyos" por "en los sus pueblos", esta variación está únicamente en I.

${ }^{149}$ Cabe decir prácticamente lo mismo que en la cita 48 al respecto de López, esta parte del prólogo está tan contaminada y plagada de errores que no sirve para filiar. Vale decir que Montalvo posee mayor fidelidad con respecto a los testimonios conservados, López recorta los detalles de los días, etc.
} 


\section{Prólogo de López (1555, encargo de la regente Juana de Austria bajo Carlos I)}

Dios es comienzo e medio e acabamiento de todas las $\operatorname{cosas}^{150}$ e sin el ninguna cosa ${ }^{151}$ puede ser, ca por el su poder son fechas e por su saber son gobernadas e por la su bondad son mantenidas ${ }^{152}$. Onde todo ome que algun buen fecho quisiere comenzar primero debe poner e adelantar a Dios en el rogandole e pidiendole merced que le de saber e voluntad e poder porque lo pueda bien acabar. Por ende, nos, don Alfonso por la gracia de dios rey de Castilla e de Toledo e de Leon e de Galizia e de Sevilla e de Cordoba e de Murcia e de Iaen, del Algarbe, entendiendo los grandes lugares que tienen de Dios los reyes en el mundo e los bienes que del reciben en muchas maneras señaladamente en la muy gran honrra que a $\operatorname{ellos}^{153}$ faze queriendo que ellos ${ }^{154}$ sean llamados reyes que es el su nombre. E otrosi por la iusticia que han de fazer para mantener los pueblos de que son señores que es la su obra. E conociendo la muy gran carga que les es con esto si bien no lo fiziessen no tan solamente por el miedo de Dios que es tan poderoso e justiciero a cuyo iuyzio han de venir e de quien se no pueden por ninguna manera asconder ni escusar que si mal fizieren no ayan la pena que merecen mas aun por la vergüenza e la afrenta de las gentes del mundo que juzgan las cosas mas por voluntad

${ }^{150}$ Omite "del mundo", dicha omisión se encuentra en todos los testimonios del subarquetipo $\beta$ (excepto, claro está, el Silense que en esta parte es ilegible).

${ }^{151}$ Agrega "cosa", dicho agregado se encuentra solo en G, H, I y J. En el caso de L, el agregado está, pero con un cambio de forma que podría ser un error de copia.

${ }^{152}$ El texto crítico establece una inversión "por el su saber son fechas [...] poder [...]". Ahora bien, este pasaje fue tan deteriorado que debemos considerar la posibilidad de que la tarea de copista no era encargada a los más sagaces. El error es claro, se produce entre la memorización de la perícopa (supongamos) bien leída y el momento del autodictado. Por ello encontramos alteración del orden, aliteración, sustitución por sinonimia y en el caso de G, haplografía en todos los mss. Ahora bien, por reconstrucción basada en nuestro iudicium, lo correcto es "por el su saber son fechas et por el su poder governadas". Esto revela la esencia del pensamiento alfonsí ya que el saber es principio y base de la autoridad en su discurso. En ese punto, desarrolla el "Argumento de omnisciencia" tal y como lo ha estudiado Lodares (1996: 113). Esto lo damos por hecho. Sin embargo, no nos asegura que López corrigió o eligió sobre la base de esto. De hecho, pudo copiar uno de los dos únicos mss. que lo coloca de ese modo, pudo usar otro y equivocarse en el suyo propio o pudo, efectivamente, corregir alguno malo (más o menos notorio, no sabemos cuál). Por lo tanto, más allá de dejar asentada esta variante, resulta imposible deducir algo a partir de este ejemplo, pues el error produce una variación adiáfora aunque parezca poseer una gran potencia esclarecedora. Los mss. en cuestión son K y G (I tiene la misma estructura también pero suma otra variante adiáfora por sustitución). F y H aliteran "poder" así que no sabemos cuál era el orden original. L posee la estructura tal y como la definimos nosotros en el texto crítico (cambia "governadas" por "guardadas") y D expone un pasaje completamente distinto. El resto de los mss. no se leen en ese punto por diversos motivos (ver nota 6 de la edición del prólogo "B").

${ }^{153} \mathrm{El}$ texto crítico establece "que les faze". Esta variante que carece de absoluta importancia es marcada ya que lo que resulta interesante en este análisis, que implica mss. e impresos, es que en todos los testimonios aparece muy clara la abreviatura de "que les", esto es "q ${ }^{-}$les", en D aparece sin abreviar. Sin embargo, en G y en L la abreviatura es menos clara " $q$ " $1 \mathrm{~s}$ ", pero esta pura conjetura no puede poseer mucho valor.

${ }^{154}$ Este agregado es un error del editor. Es adiáfora la variación (en este caso discursiva, proyecta constituyentes potenciales de la oración), pero vale mencionarla para mostrar cómo esta tarea nunca acaba (Roudil, 2000). 
que por derecho. E aviendo sabor de nos guardar destas afrentas ${ }^{155}$ e del daño que ende nos puede venir E otrosi la muy grande merced que nos Dios fizo en querer que viniessemos del linage onde venimos e el lugar en que nos puso faziendonos señor de tantas buenas gentes e de tan grandes tierras como el quiso meter so nuestro señorio. Catamos carreras porque nos e los que despues de nos reynassen en nuestro señorio sopiessemos ciertamente los derechos para mantener los pueblos en Iusticia e en paz. Otrosi porque los entendimientos de los omes que son departidos en muchas maneras se acordassen en uno con razon verdadera e derecha para conoscer primeramente a Dios cuyos son los cuerpos e las almas, que es señor sobre todos e de si a los señores temporales de quien resciben bien fecho en muchas maneras, cada uno en su estado, segund su merescimiento. Otrosi que fiziesse aquellas cosas que fuessen tenidas por buenas e de que les viniesse bien e se guardasse de fazer yerro que les estuviesse mal e de que les pudiesse venir daño por su culpa. E porque todas estas cosas no podrían fazerlos omes cumplidamente sino conosciesen cada uno en su estado qual es lo que le conviene que faga en el, e de lo que se deve de guardar. E otrosi de los estados de las otras cosas a que deven obedecer. Por esso fablamos todas las cosas e razones que a esto pertenescen e fezimos ende este libro porque nos ayudemos nos del e los otros que despues denos viniessen conosciendo las cosas e oyendolas ciertamente ${ }^{157}$. Ca mucho conviene a los reyes e señaladamente a los desta tierra, conoscer las cosas segund son e estremar el derecho del tuerto e la mentira de la verdad, ca el que no supiere esto no podra fazer la iusticia bien e cumplidamente que es a dar a cada uno lo que le conviene cumplidamente ${ }^{158}$ e lo que meresce. E porque las nuestras gentes son leales e de grandes coraçones, por eso a menester que la lealtad se mantenga con verdad, e la fortaleza de las voluntades con derecho e con iustitia, ca los reyes sabiendo las cosas que son verdaderas e derechas, fazerlas han ellos, e no consentiran a los otros que passen contra ellas, segund dixo el rey Salomon, que fue sabio y muy justiciero, que quando el rey estuviesse en su Cadira de iusticia que ante el su acatamiento se desatan todos los males. Ca pues que lo entendiere guardara a si e a los otros de daño. E por esta razon fezimos señaladamente este libro, porque siempre los reyes de nuestro señorio se caten en el ansi como en es-

${ }^{155}$ Un caso similar al anterior. Todos los testimonios agregan "dos" antes de "afrentas". Esto en principio es un error discursivo, en este caso es una proyección de sintagma nominal de referencia específica. Es decir, variación adiáfora. Sin embargo, resulta interesante, una vez más, que frente a la homogeneidad en ese locus en todos los testimonios, solo K, L y M la evitan, siendo que son mss. que están muy cercanos y que, hasta ahora, poseen coincidencias significativas con la edición de López. Si bien es cierto que es un error que dos o más copistas podrían haber cometido independientemente entre sí, la tendencia sumada a la cantidad también debe ser tenida en cuenta.

${ }^{156}$ Todos los testimonios coinciden en colocar "razones", excepto L que coloca "cosas". Podríamos considerar que el texto de López comporta una fuerte tarea crítica (amén del método y del aparato crítico, naturalmente).

${ }^{157}$ Todos los mss. que contienen este pasaje (ver notas 27, 32, 33, 34 y 35) coinciden en colocar "et yendo a ellas ciertamente". Una vez más, este cambio produce una variante adiáfora que se podría explicar por adición de integrante léxico (de modo discursivo) o, me inclino más, por vía de error de copia común. En este caso, mezcla de lectio facilior, anticipación y posible errónea segmentación. Sin embargo, la marcamos pues cabe considerarlo como cambio consciente, ya que el valor de conocer sumado al oír hace referencia a las figuras procesales fundantes en la relación entre fama y proceso inquisitorio. Nuevamente se vuelve conjetural, pero más abajo quiero detenerme en las implicaciones posibles de este cambio que solo aparece en López.

${ }^{158}$ Repetición. 
pejo e vean las cosas que an en si de enmendar e las enmienden e segund aquesto que fagan en los suyos. Mas porque tantas razones ni tan buenas como avia menester para mostrar este fecho, no podiamos nos fablar por nuestro entendimiento ni por nuestro seso para cumplir tan grand obra e tan buena, acorrimonos de la merced de Dios e del bendicto su fijo nuestro señor Iesu Christo, en cuyo esfuerço nos lo començamos, e de la virgen santa Maria su madre, que es medianera entrenos e el ${ }^{159}$ e de toda su corte celestial, e otrosi de los dichos de ellos. E tomamos de las palabras de los buenos dichos que dixeron los sabios que entendieron las cosas razonadamente segund natura e de los derechos de las leyes e de los buenos fueros que fizieron los grandes señores e los otros omes sabidores de derecho en las tierras que ovieron de juzgar. E pusimos cada una de estas razones donde conviene. E a esto nos movio señaladamente tres $\operatorname{cosas}^{160}$. La primera el muy noble e bienaventurado rey don Fernando nuestro padre que era cumplido de justicia e de derecho que lo quisiera fazer si mas biviera. E mando a nos que lo fiziessemos. La segunda, por dar ayuda e esfuerço ${ }^{161}$ a los que despues de nos reynassen porque pudiesen mejor sufrir la gran lazeria e trabajo que an de mantener los reynos, los que lo bien quisiessen fazer. La tercera, por dar carrera a los omes de conoscer el derecho e la razon, e se supiessen de guardar de fazer tuerto ni yerro ${ }^{162}$ e supiessen amar e obedescer a los otros señores que despues de nos viniessen. E este libro fue començado a fazer e a componer [en] vispera de S. Iuan Baptista, a quatro años e xxiii dias andados del comienço del nuestro reynado que començo quando andava la Era de Adam en cinco mill e veynte un años Hebraycos e dozientos e ochenta dias. E la Era del diluvio en quatro mill e trezientos e cinquenta e tres años Romanos, e ciento cinquenta dias mas. E la Era de Nabucodonosor en mill e novecientos e noventa dias mas. E la Era de Felipo el grand rey de Grecia en mill e quinientos e sesenta e quatro años Romanos e veynte y dos dias mas. E la Era del gran Alexandre de Macedonia en mill e quinientos e sesenta e dos años Romanos e dozientos e quarenta e tres dias. E la Era de Cesar en mill e dozientos e ochenta e nueve años Romanos e ciento e cinquenta dias mas. E la Era de la Encarnacion en mill e dozientos e cinquenta e un años Romanos e ciento e cinquenta e dos dias mas. E la Era de los Aravigos en seyscientos e veynte nueve años Romanos, e trezientos e un dias mas. E fue acabado desde que fue començado a siete años cumplidos ${ }^{163}$.

\footnotetext{
${ }^{159}$ Solo J, K, L y M agregan “et el”.

${ }^{160}$ Otra vez parece haber una serie de mss. que usa "razones" y otra que usa "cosas". Como no son sinónimos vale la pena recalcarlo. Los mss. que dicen "cosas" son J, K y M.

${ }^{161}$ Aquí tenemos otra variante adiáfora por alteración del orden de los sintagmas. Pero, una vez más, la marcamos pues se agrupa con lo expuesto en E, J, K y L.

${ }^{162}$ El grupo J, K, L y M posee este agregado "nin yerro". Esto es una proyección de constituyente sintagmático.

${ }^{163}$ Esta última parte es bastante compleja. La propia tradición manuscrita lo es. Las razones son evidentes: las abreviaturas para números (sumadas a las pérdidas y manchones) generaron que haya serias diferencias entre los diversos testimonios y asimismo encontramos diversas formas de datación. En lo que respecta al prólogo de López lo que parece haber es un recorte del posible interminable listado de dataciones. Decimos esto ya que el modelo expuesto por López no obedece de manera más o menos fiel a ningún testimonio conservado y utilizado.
} 